\title{
Plains Tectonism on Venus: The Deformation Belts of Lavinia Planitia
}

\author{
STEVEN W. SquYRES and DAVID G. JANKowSKI \\ Center for Radiophysics and Space Research, Cornell University, Ithaca, New York \\ Mark Simons, SEAN C. Solomon, Bradford H. Hager \\ Department of Earth, Atmospheric, and Planetary Sciences, Massachusetts Institute of Technology, Cambridge
}

George E. MCGILL

Department of Geology and Geography, University of Massachusetts, Amherst

\begin{abstract}
High-resolution radar images from the Magellan spacecraft have revealed the first details of the morphology of the Lavinia Planitia region of Venus. A number of geologic units can be distinguished, including volcanic plains units with a range of ages. Transecting these plains over much of the Lavinia region are two types of generally orthogonal features that we interpret to be compressional wrinkle ridges and extensional grooves. The dominant tectonic features of Lavinia are broad elevated belts of intense deformation that transect the plains with complex geometry. They are many tens to a few hundred kilometers wide, as much as $1000 \mathrm{~km}$ long, and elevated hundreds of meters above the surrounding plains. Two classes of deformation belts are seen in the Lavinia region. "Ridge belts" are composed of parallel ridges, each a few hundred meters in elevation, that we interpret to be folds. Typical fold spacings are $5-10 \mathrm{~km}$. "Fracture belts" are dominated instead by intense faulting, with faults in some instances paired to form narrow grabens. There is also some evidence for modest amounts of horizontal shear distributed across both ridge and fracture belts. Crosscutting relationships among the belts show there to be a range in belt ages. In western Lavinia in particular, many ridge and fracture belts appear to bear a relationship to the much smaller wrinkle ridges and grooves on the surrounding plains: Ridge morphology tends to dominate belts that lie more nearly parallel to local plains wrinkle ridges, and fracture morphology tends to dominate belts that lie more nearly parallel to local plains grooves. We use simple models to explore the formation of ridge and fracture belts. We show that convective motions in the mantle can couple to the crust to cause horizontal stresses of a magnitude sufficient to induce the formation of deformation belts like those observed in Lavinia. We also use the small-scale wavelengths of deformation observed within individual ridge belts to place an approximate lower limit on the venusian thermal gradient in the Lavinia region at the time of deformation.
\end{abstract}

\section{INTRODUCTION}

Of the many linear tectonic features known to be present on Venus prior to the Magellan mission, most attention was devoted to the spectacular mountain belts found in the Maxwell Montes and elsewhere [e.g., Campbell et al., 1983; Barsukov et al., 1986; Basilevsky, 1986]. It has also been known, however, that there is considerable evidence for tectonism on the venusian plains. The "ridge belts" described on the basis of Arecibo and Venera 15/16 data are particularly good examples. In Venera 15/16 images they are most abundant in Atalanta Planitia, a lowland region in the northern hemisphere. Like the highland mountain belts, ridge belts were inferred to consist of subparallel ridges and grooves. However, they appeared to be elevated comparatively little above the surrounding plains. The ridges and grooves that form them are approximately parallel to the margins of the belts, and can be continu-

Coyright 1992 by the American Geophysical Union.

Paper number 92JE00481.

0148-0227/92/92JE-00481\$05.00 ous along strike for hundreds of kilometers. Spacings of individual ridges, as determined from the low-resolution Arecibo and Venera 15/16 data, were seen to be typically a few tens of kilometers. The belts in Atalanta Planitia are themselves crudely parallel, with typical belt-to-belt spacings of $300-400 \mathrm{~km}$. In some locations, both in Atalanta and elsewhere, individual ridges and furrows not organized into belts also were observed. A compressional origin for the ridge belts was the most widely accepted hypothesis prior to Magellan [e.g., Barsukov et al., 1986; Crumpler et al., 1986], although an extensional origin also was suggested [Sukhanov and Pronin, 1989].

The first deformation belts on the venusian plains observed by the Magellan spacecraft have been those on Lavinia Planitia, in Venus's southern hemisphere. Solomon et al. [1991] presented a preliminary description of some of the belts of Lavinia. They noted that there were two classes of belts and concluded that both had a compressional origin. In this paper we discuss the belts of Lavinia in detail, using improved data and expanded imaging coverage. Because the Magellan images have shown the belts to have significantly greater mor- 
phologic diversity than was apparent in previous data sets, we have followed Solomon et al. [1991] by adopting the general term "deformation belts" for these features, retaining the term "ridge belt" for one of the morphologic subtypes.

In preparing this paper, we have primarily made use of three Magellan data products: full-resolution mosaicked image data records (F-MIDRs), compressed mosaicked image data records (C1-MIDRs), and global topographic data records (GTDRs). F-MIDRs are synthetic aperture radar (SAR) image mosaics that retain the full spatial resolution of the radar system, sampled at $75 \mathrm{~m} /$ pixel. C1-MIDRs contain the SAR data resampled at $225 \mathrm{~m} /$ pixel. Altimetry is taken from GTDRs, which contain measurements of local planetary radius made by the Magellan altimeter, sampled to a uniform planetary grid and spatially filtered for smoothing. The along-track spatial resolution of the altimeter varies from about $\sim 8 \mathrm{~km}$ near the equator to $\sim 20 \mathrm{~km}$ at high latitudes, and the across-track resolution varies similarly from $\sim 13$ to $\sim 30 \mathrm{~km}$ [Pettengill et al., 1991]. Due to a software error, the altimetric results for Lavinia and elsewhere presented by Solomon et al. [1991] are incorrect at small spatial scales, and we present improved altimetric data here.

\section{Geologic Units}

Most of Lavinia Planitia is seen in the Magellan C1MIDR 45S350, shown in Figure 1. Several geologic units, defined on the basis of radar brightness, smallscale texture, characteristics and abundance of superposed structural features, and apparent relative ages, can be distinguished in this area. Because the SAR incidence angle in this region averages about $25^{\circ}$, the radar return relates primarily to wavelength-scale roughness and, less commonly, to meter-scale and larger slopes; the effects of compositional variations should be minor. Consequently, many, and perhaps most, of the geological units are distinguished by differences in surface characteristics rather than differences in inherent material properties. For some units, such as lobate flows, radar units very likely correspond to those defined using more conventional geological criteria. Other units, however,

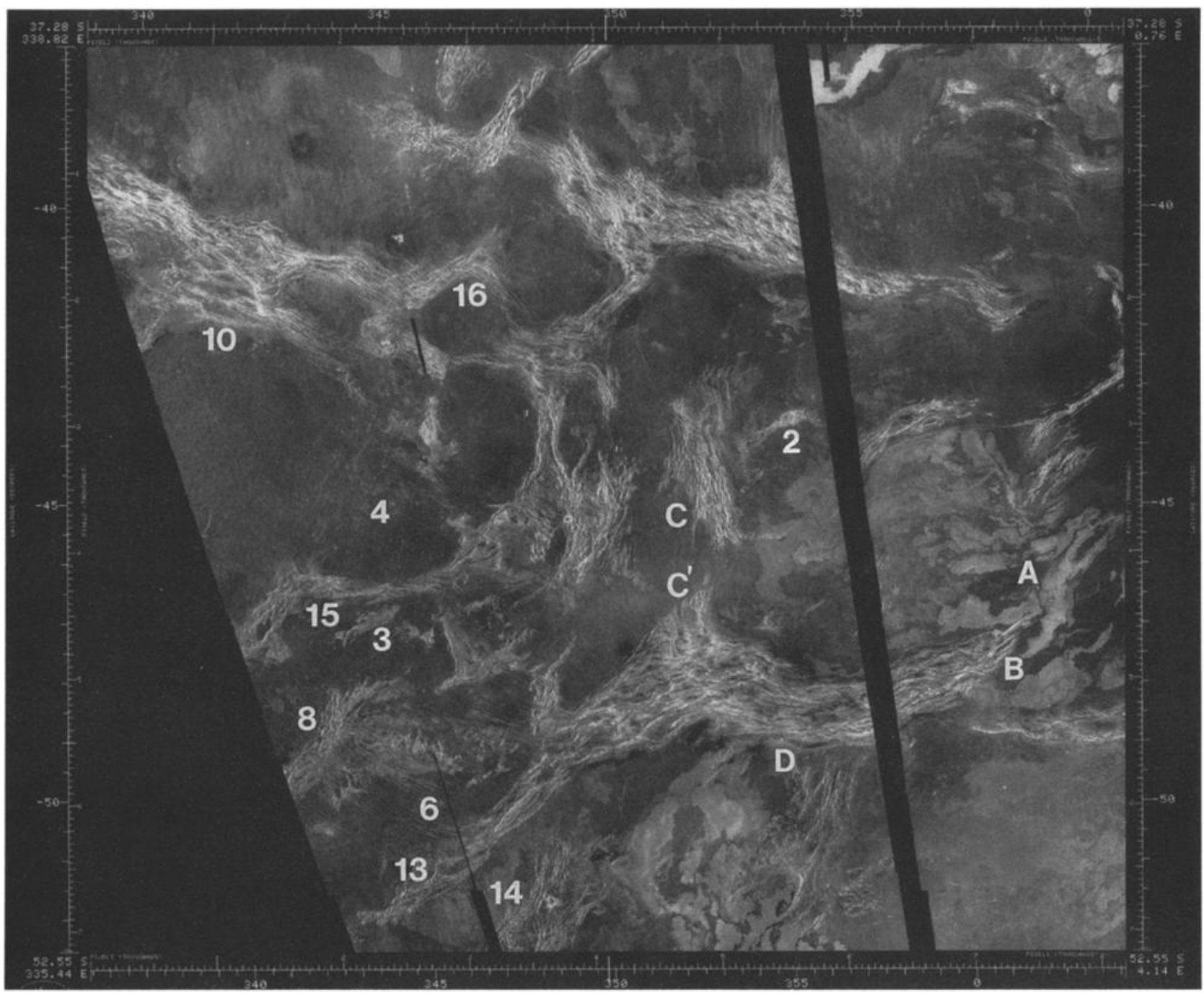

Fig. 1. Magellan radar mosaic of Lavinia Planitia, in sinusoidal equal-area projection. The image is centered at $45^{\circ} \mathrm{S}, 350^{\circ} \mathrm{E}$, and the width of the image is $1843 \mathrm{~km}$. Letters refer to features discussed in the text. Numbers give the locations of other figures. As for all other radar mosaics in this paper, north is at the top and the radar illumination direction is from the left. 
may represent similar materials that have experienced different structural evolutions, with consequently different surface textures at centimeter and meter scales.

We divide the terrains of Lavinia Planitia into four broad groups: complex ridged terrains (CRT), textured terrains, regional plains, and digitate plains. We have

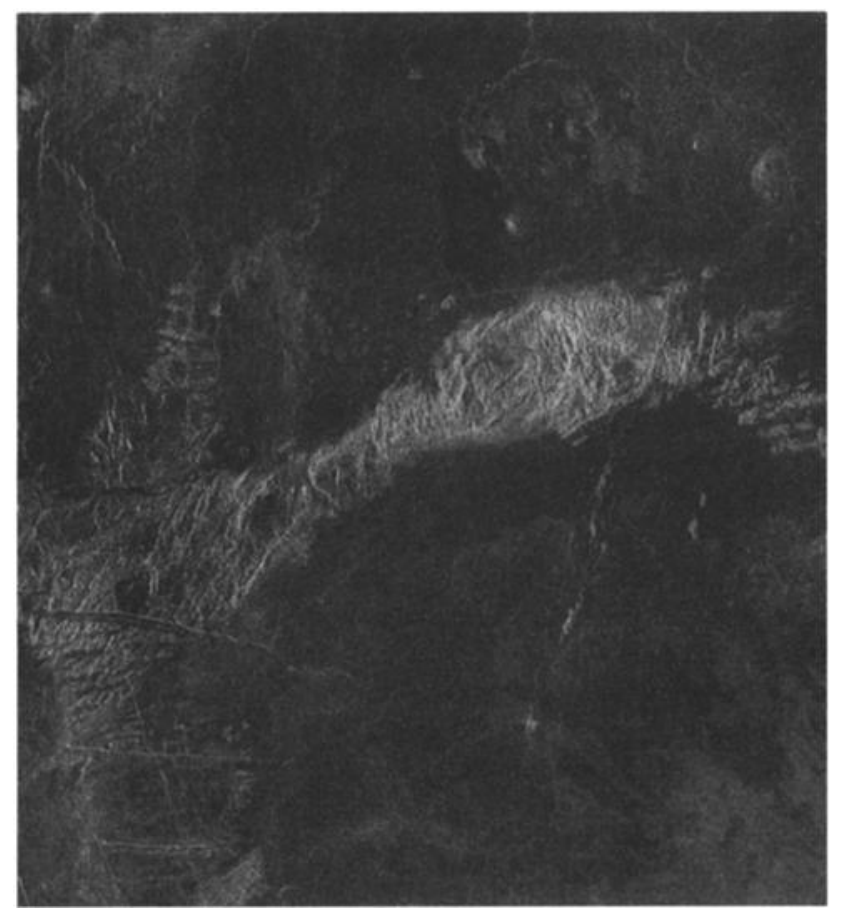

Fig. 2. Complex ridged terrain, exposed through younger plains materials. Width of the image is $190 \mathrm{~km}$. See Figure 1 for location. defined one CRT unit, one textured unit, two regional plains units, and one digitate plains unit. The follow. ing paragraphs describe the units in approximate order from oldest to youngest.

\section{Complex Ridged Terrain}

CRT occurs in Lavinia Planitia as scattered inliers surrounded and embayed by younger plains deposits (Figure 2). These inliers are characterized by a strong linear trend of kilometer-scale or narrower ridges and troughs, with a weaker secondary trend of lineaments at a high angle to the strong primary trend present locally. CRT is much brighter than surrounding plains on the SAR images unless the plains are intensely fractured.

\section{Textured Terrain}

Many areas in Lavinia are as radar-bright as CRT but do not exhibit the same kilometer-scale ridge-andtrough pattern. In places, it is possible to resolve a very regular fabric of bright lines at a scale of about $400 \mathrm{~m}$, and it is this fabric that gives this material its textured appearance (Figure 3). At the scale of the Magellan SAR images, this fabric can be considered penetrative. The structural cause of the fabric cannot be determined, but a uniformly spaced set of joints is one possibility. Textured terrain occurs in two distinct physiographic forms: (1) as plains that are significantly brighter than adjacent regional plains materials, and (2) as long, narrow ridges generally grouped together into ridge belts (see below). Crosscutting and embayment relationships in some instances indicate that textured terrain is younger than CRT and older than regional plains. Nevertheless, both textured terrain and regional

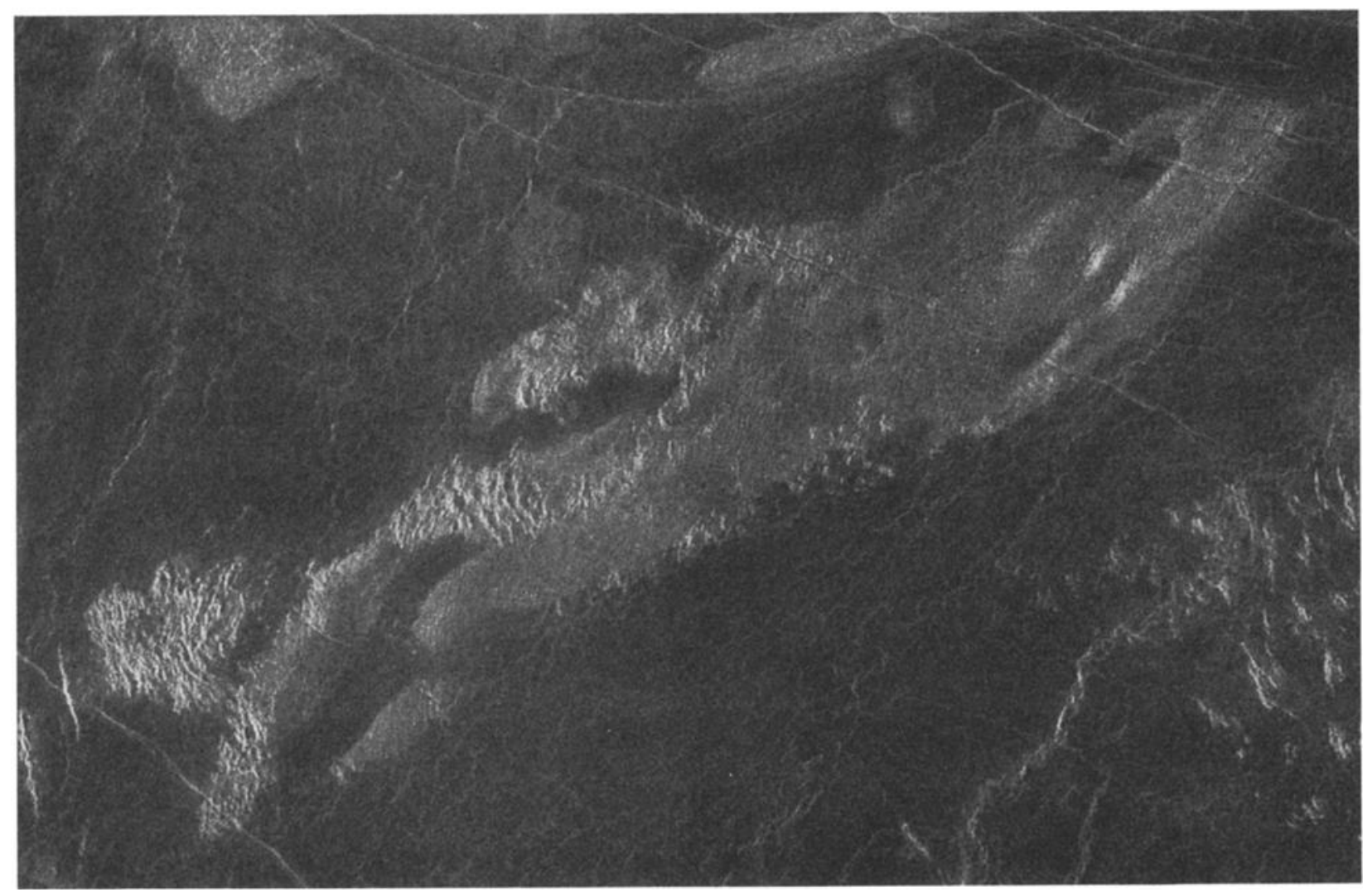

Fig. 3. Textured terrain. Width of the image is $150 \mathrm{~km}$. See Figure 1 for location. 
plains are of variable brightness, and therefore there are places where it can be difficult to define the contact between them. The penetrative fabric and, indeed, the overall textured aspect are not evident in places where textured terrain is intermediate in character between well-defined textured terrain and bright mottled plains.

\section{Regional Plains}

The areally dominant terrain type in Lavinia Planitia consists of moderately radar-dark to moderately radarbright plains. Regional plains materials are most likely of volcanic origin, but morphologic forms resembling flows are rare.

Mottled plains. These are moderately bright to locally bright plains with a "blotchy" or mottled texture at kilometer and smaller scales (Figure 4). They are generally characterized by abundant superposed wrinkle ridges (see below). In places, mottled plains include large numbers of small shields or domes from a few to about $20 \mathrm{~km}$ in diameter. Locally, it is possible to define two members of mottled plains that differ in radar brightness. At many such locations it is the brighter and apparently older of the two members that includes the small shields and domes, which are surrounded by the darker and apparently younger member (Figure 4).

Dark plains. These are plains that are darker, have more uniform radar backscatter, and have fewer super-

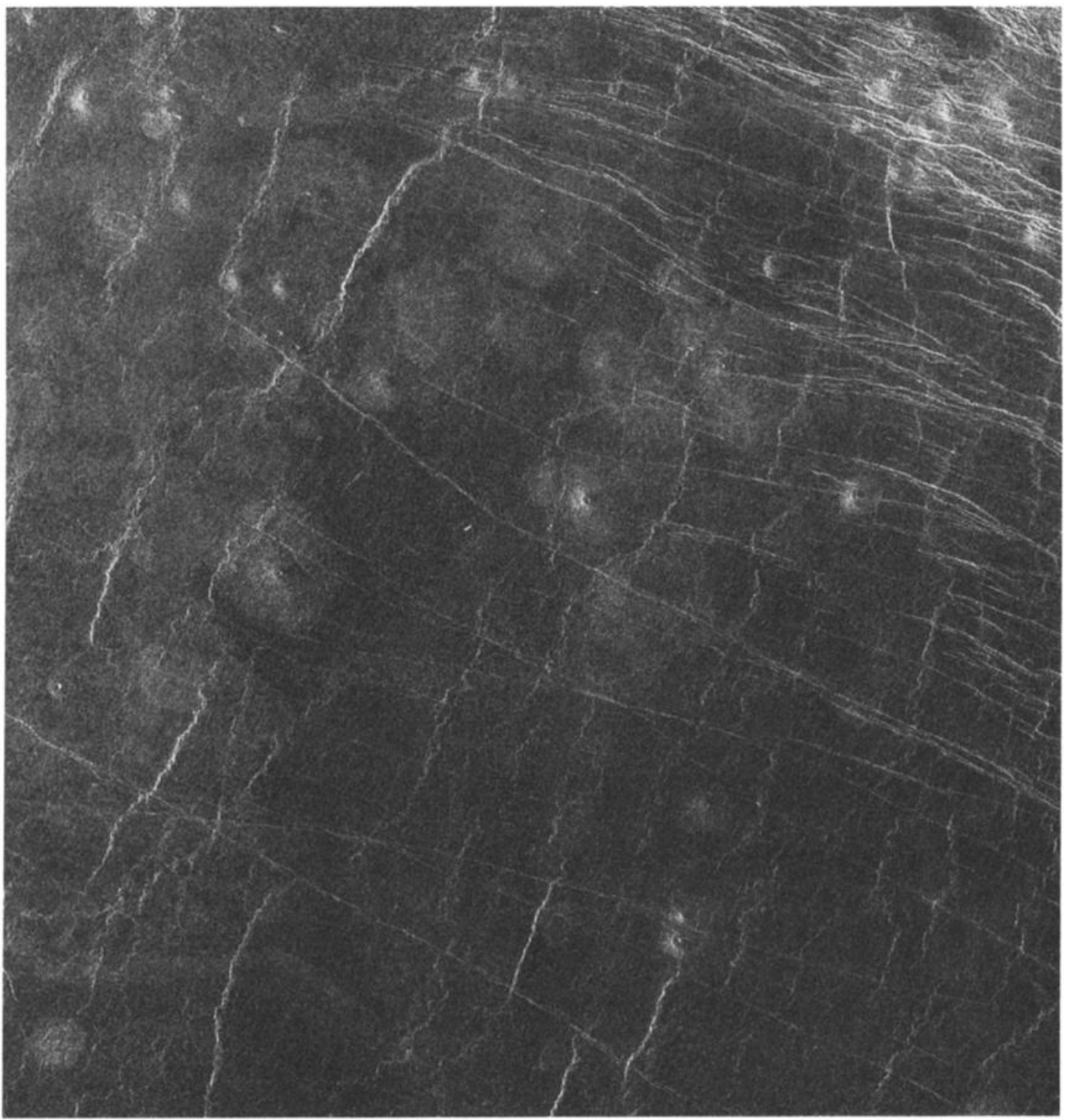

Fig. 4. Mottled plains materials. Darker member in the lower right appears to surround small domes and shields in the lighter member in the upper left. Also note abundant wrinkle ridges. Width of the image is $155 \mathrm{~km}$. See Figure 1 for location. 
posed wrinkle ridges than mottled plains. Dark plains commonly occur as small patches adjacent to or within fracture belts (see below), where they are superposed on the fractures. In other places, however, dark plains appear to grade into the dark member of the mottled plains (Figure 4).

\section{Digitate plains}

This unit consists of complexes of digitate to locally lobate flows, many attaining lengths of hundreds of kilometers ( $A$ in Figure 1). Most of these flows are brighter on the SAR image, and hence probably rougher at centimeter scales, than all other plains units. Feeder channels (or collapsed lava tubes) are apparent in several places, and many flow complexes can be traced upslope to sources of apparent volcanic origin. Superposed wrinkle ridges are sparse, and flow patterns clearly indicate that adjacent deformation belts already existed as topographic ridges when these flows were emplaced.

\section{Tectonic Features}

\section{Wrinkle Ridges}

Most of the plains areas of Lavinia contain long, narrow, sinuous linear features that appear brighter than the background plains (Figure 4). These features are generally less than $1 \mathrm{~km}$ wide and a few tens of kilometers long, although some reach widths of several kilometers and lengths in excess of $100 \mathrm{~km}$. Typical spacings range from several to about $20 \mathrm{~km}$ and locally up to
$50 \mathrm{~km}$. Where the topography of these features can be inferred from brightness variations in the SAR images, they are clearly seen to have positive relief, although most appear as simple sinuous bright lineaments. We interpret these features as compressional ridges, analogous to the wrinkle ridges commonly seen on the lunar maria and Martian ridged plains [e.g., Plescia and Golombek, 1986; Watters, 1988].

The wrinkle ridges of Lavinia Planitia show strong preferred orientations within subareas of the region (Figure 5a). A very strong NNE-SSW trend is apparent in the western portion of the map, while the trend is $\mathrm{N}$ $S$ in the central portion and NNW-SSE in the northeast portion. These trends are also evident in rose diagrams of ridge segment orientations (Figure $5 b$ ).

Wrinkle ridges appear to have formed throughout the evolution of plains, because all plains units have them, including digitate plains. However, there is a clear decrease in the number of ridges from mottled plains to dark plains to digitate plains; that is, there is a decrease in ridge concentration with decreasing inferred age. Furthermore, the trends of the ridges appear related to locality rather than stratigraphic age because the dominant trend of the sparse ridges on digitate plains is similar to the dominant trend of the more abundant ridges on adjacent regional plains. These relationships suggest that ridge formation is an ongoing process related to local stress fields that did not change significantly during the deposition of the various plains materials. Although local stress fields varied geograph-

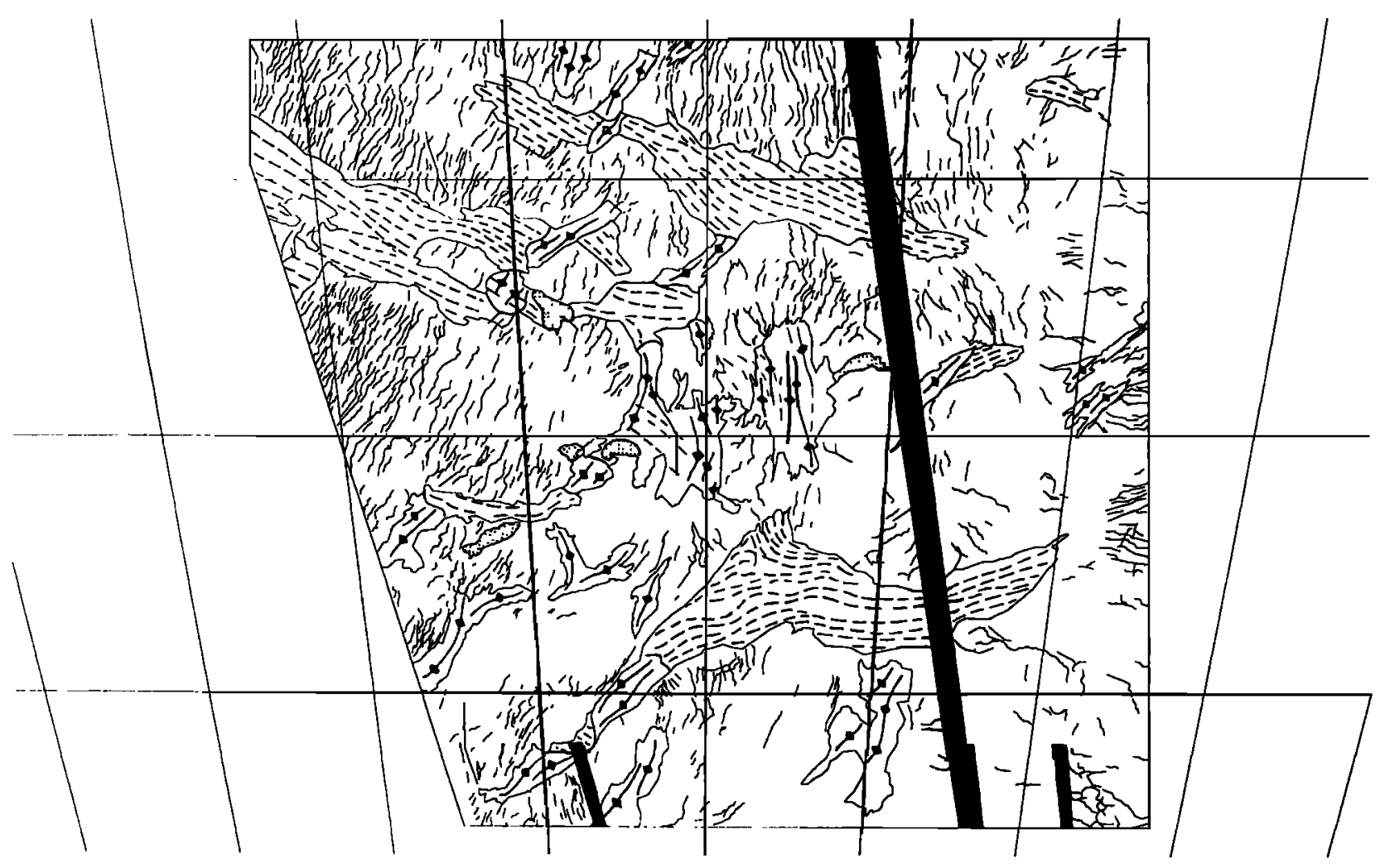

Fig. 5a. Map of wrinkle ridges (lines on plains) and deformation belts in Figure 1. For fracture belts, fracture trends are shown by dashed line patterns; for ridge belts, ridge trends are shown by lines with diamond symbols. Shaded regions are complex ridged terrain. 


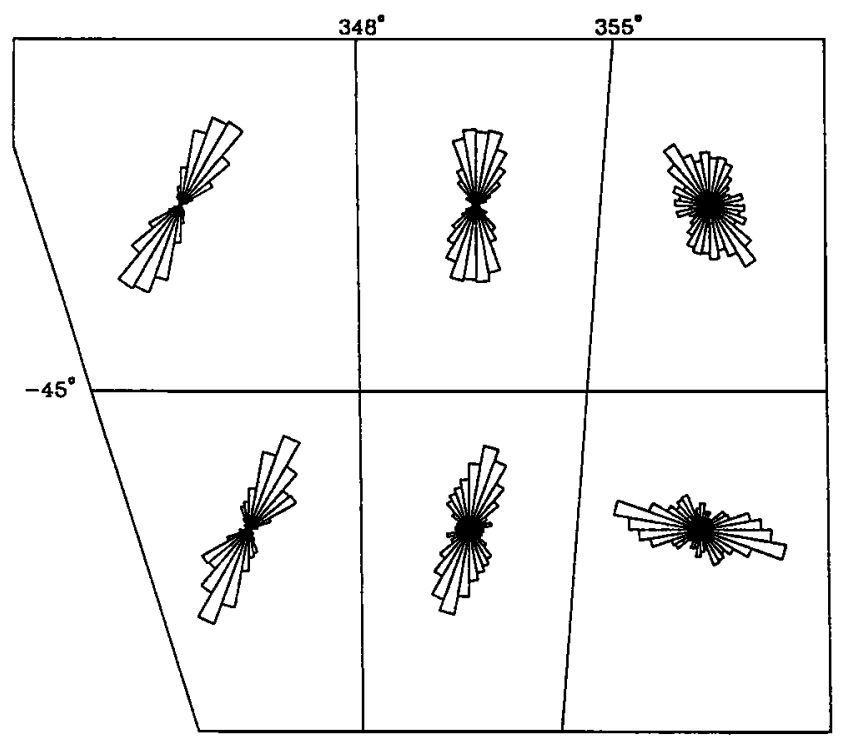

Fig. 5b. Rose diagrams of wrinkle ridge orientations in six subareas of Figure 1. Diagrams are normalized to have equal total lengths.

ically during plains formation, they apparently did not vary substantially with time in any one locality.

\section{Grooves}

Over much of the western part of Lavinia Planitia are WNW trending radar-bright lineaments. They are geometrically distinct from the wrinkle ridges in that they are both longer and substantially straighter. In many instances they are too narrow to be resolved as anything but radar-bright lines, but where they can be resolved they are seen to be narrow grooves (Figure 6). Lengths from 25 to $75 \mathrm{~km}$ are common in some areas, while lengths of 150 to $200 \mathrm{~km}$ are common in others. A few grooves have lengths exceeding $500 \mathrm{~km}$. Spacings are also variable. The longest grooves (lengths exceeding $200 \mathrm{~km}$ ) show typical spacings of 30 to $100 \mathrm{~km}$. Heavily deformed regions show typical spacings of 1 to $3 \mathbf{~ k m}$. Groove widths are generally about 300 to $700 \mathrm{~m}$. There are no instances of these grooves cutting digitate flows, but it is not clear if this is because the flows are younger or simply because these grooves were never formed in the eastern portions of Lavinia where such flows occur. The grooves clearly are younger than mottled and dark plains. Abutting relationships with wrinkle ridges suggest that some ridges are older than adjacent grooves, some younger. We interpret these grooves to be narrow grabens.

A map of grooves in Lavinia Planitia shows the parallel nature of the grooves in the western part of the region (Figure 7). It is noteworthy that in all areas where grooves are present, their orientations are perpendicular to those of the wrinkle ridges. Thus, a significant section of Lavinia Planitia is characterized by a distinctive pattern of orthogonal compressional and extensional features on the plains between the deformation belts.

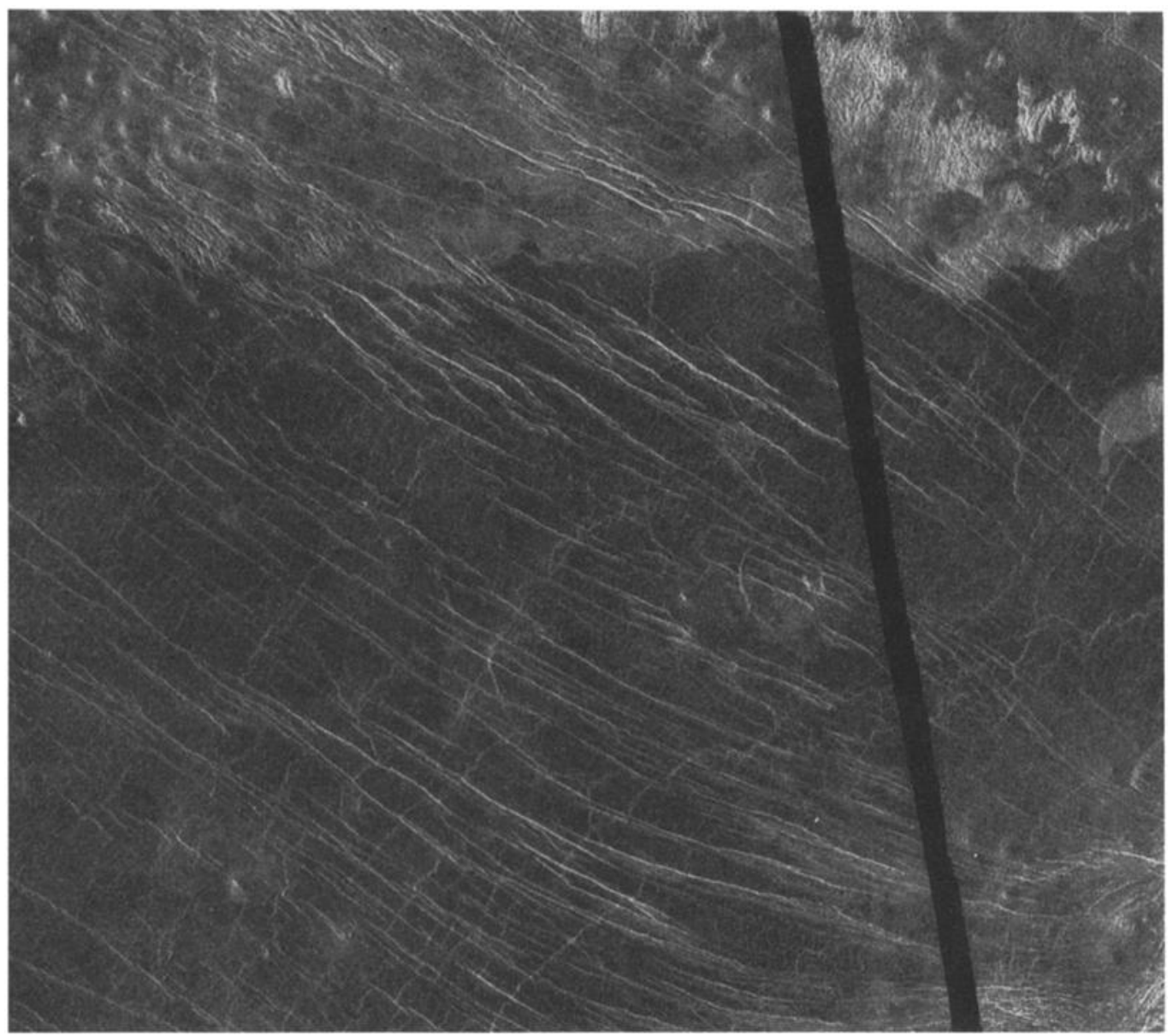

Fig. 6. Grooves on the plains. Width of the image is $205 \mathrm{~km}$. See Figure 1 for location. 


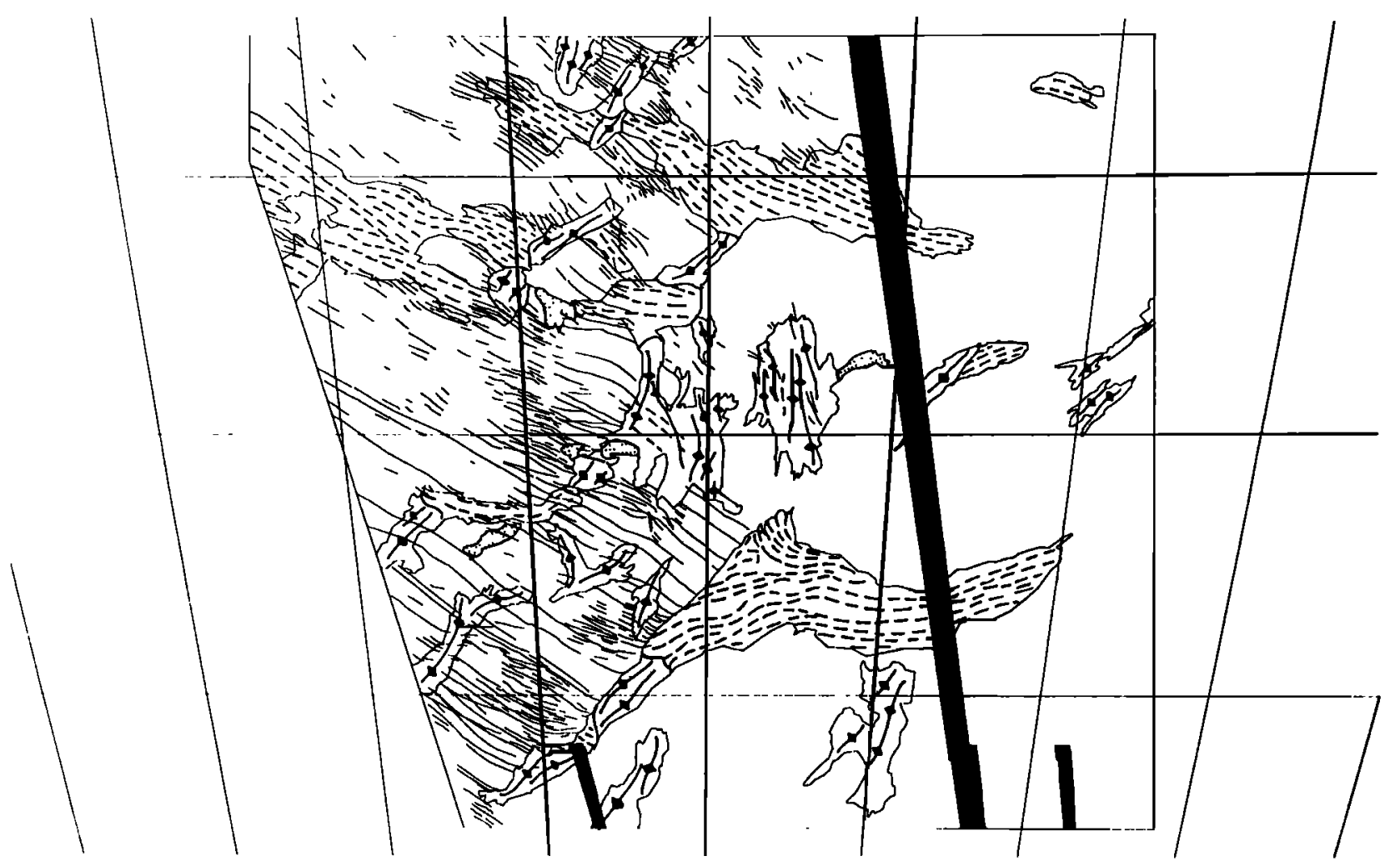

Fig. 7a. Map of grooves (lines on plains) and deformation belts in Figure 1. For fracture belts, fracture trends are shown by dashed line patterns; for ridge belts, ridge trends are shown by lines with diamond symbols. Shaded regions are complex ridged terrain.

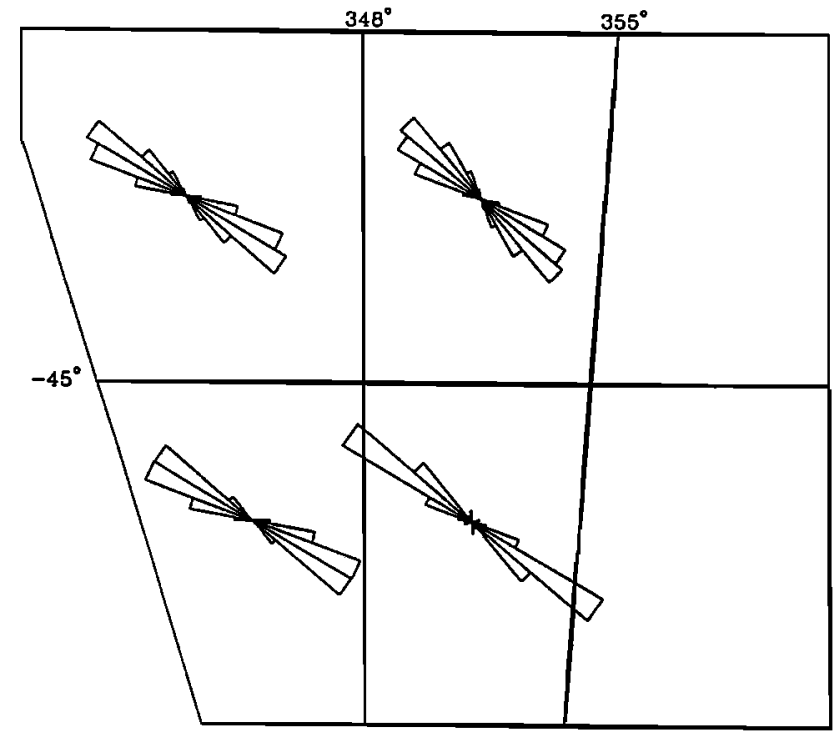

Fig. 7b. Rose diagrams of groove orientations in six subareas of Figure 1. Normalization is as in Figure 5b.

\section{Ridge Belts}

The most obvious tectonic features of Lavinia Planitia are the prominent deformation belts that transect much of the surface. These belts take two very distinct forms, which we call ridge belts and fracture belts. An example of a ridge belt is shown in Figure 8 . The ridges that compose them can vary considerably in width both from one to the next in a given belt and along the length of a single ridge. The maximum width observed is about $10 \mathrm{~km}$, and more typical widths are a few kilometers. Some ridges appear symmetric in cross section, while others appear steeper on one flank than the other. A smooth, archlike profile is most common, but some ridges show a narrow, rugged secondary ridge superimposed on the crest or on one flank of the arch, as is common for lunar wrinkle ridges. The ridges are typically rather sinuous and commonly bifurcate and merge along strike, producing a complex anastomosing pattern. Some ridges appear to consist of textured terrain material, but in most places the unit involved is not apparent.

It would be desirable to construct detailed topographic profiles across ridge belts, but the individual ridges are too narrow to be resolved by the Magellan altimeter, and the single SAR view obtained during the first mapping cycle does not permit stereo analysis. There is, however, one approach that can be used to construct such profiles. One of the belts (Figure 8) is cut by several of the tectonic grooves discussed above. While these grooves appear very straight where they lie on the adjacent plains, they take on a distinctive cuspate curvature as they cross each ridge in the belt. It is likely that this curvature is an effect of the radar viewing geometry; the low radar incidence angle at this latitude (about $\mathbf{2 3}^{\circ}$ ) results in the groove, as it passes across the elevated ridge, appearing displaced in the direction of the spacecraft.

If we make the assumption that the grooves are actually straight in map view as they cross the ridges, we can use the apparent local deviation of the groove 


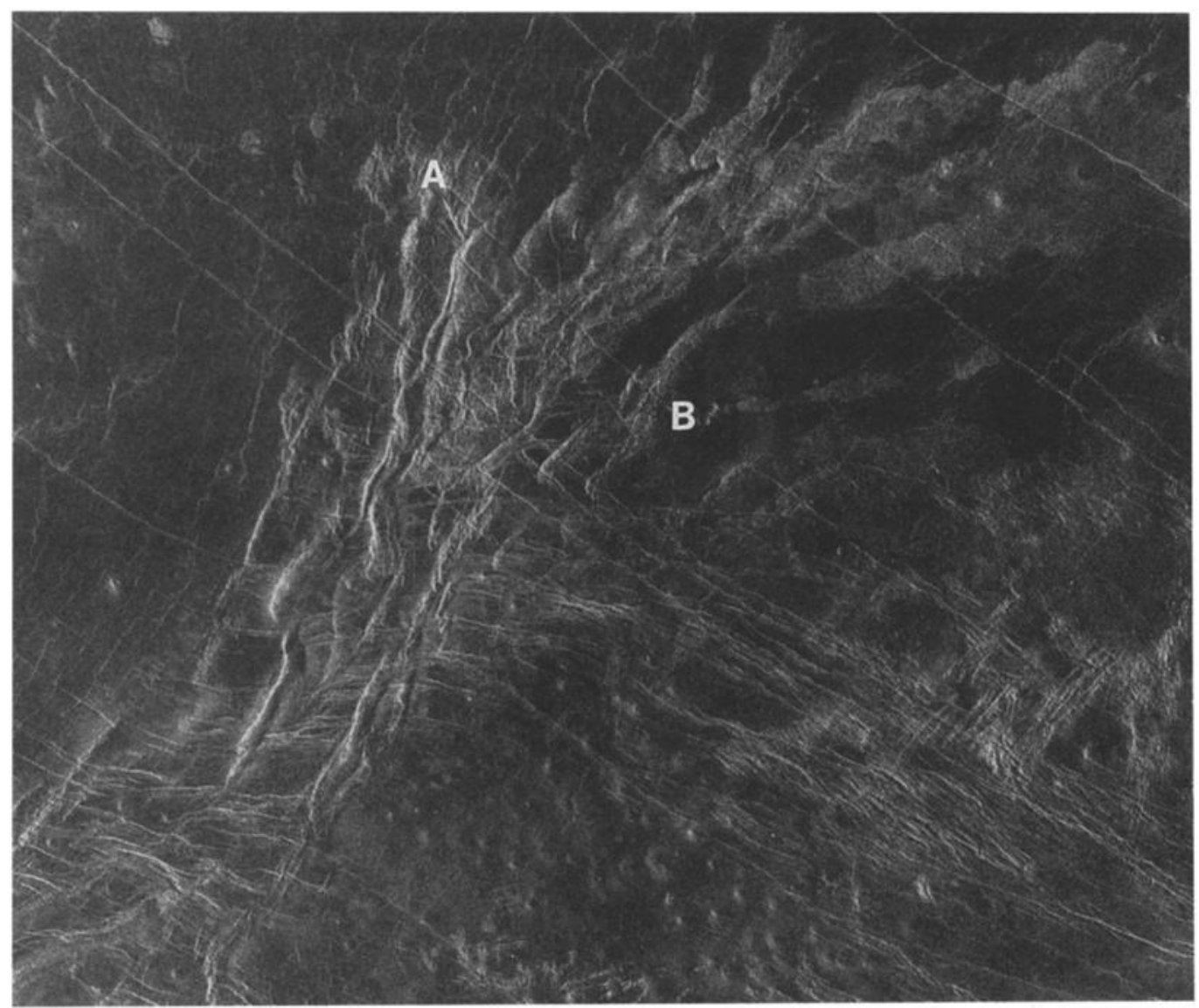

Fig. 8. A ridge belt. Width of the image is $205 \mathrm{~km}$. See Figure 1 for location. A and B are endpoints of the topographic profile in Figure 9.

trend, plus a knowledge of the radar viewing geometry, to construct a topographic profile. Such a profile is shown in Figure 9. Most of the ridges in this profile are fairly symmetric, with archlike profiles, widths of several kilometers, and heights of $200-300 \mathrm{~m}$. (This approach to producing a topographic profiles is, of course, fundamentally limited by the correctness of the assumptions on which it is based. The detailed heights and shapes of the ridges in the profile may be fairly accurate, since grooves elsewhere tend to be very straight on scales comparable to the ridge width. The overall height of the belt in the profile, however, should not be regarded as accurate, since subtle curvature of the grooves over length scales of many tens of kilometers is common.)

The individual ridges within ridge belts differ little in appearance from the largest wrinkle ridges, except that they tend to be less sinuous. Because both types of ridges are inferred to result from compressional deformation, this similarity is not too surprising. Where ridge belts deforming textured terrain are embayed by plains materials with wrinkle ridges, large, young wrinkle ridges can be distinguished from older ridges of the belt. The possibility must be entertained, however, that ridge belts can evolve from wrinkle ridges and thus be younger than the adjacent regional plains at some locations.

\section{Fracture Belts}

The other class of deformation belts found in Lavinia
Planitia is the fracture belt (Figure 10). In contrast to ridge belts, fracture belts are dominated by a complex pattern of linear to arcuate faults and fractures. Many faults appear singly, but others are paired to

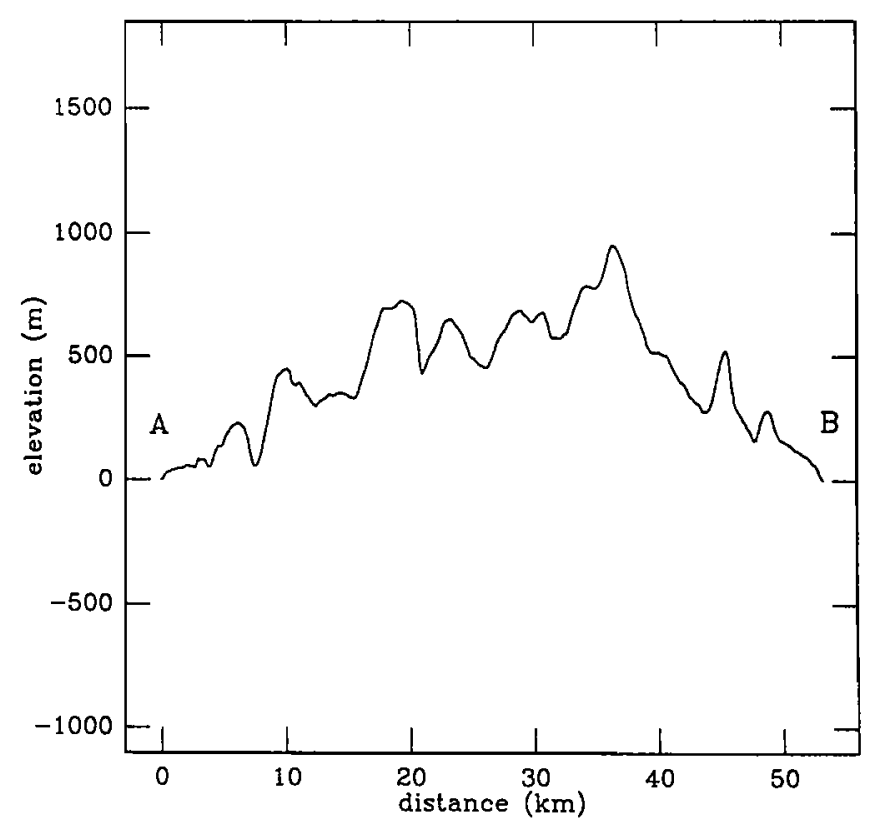

Fig. 9. Inferred topographic profile across the ridge belt in Figure 9 , constructed from the apparent displacement of a groove as it 
form grooves with widths ranging from a few kilometers incided with local highs in the altimetry, and this was down to the resolution limit of the images. The faults interpreted to mean that the faulting might be a consecommonly display complex anastomosing and crossing quence of brittle deformation across the crests of antipatterns that indicate repeated or progressive deforma- clines. However, as mentioned above, this inference was tion. Where fracture belts change trend, or where belts based on incorrectly processed altimetric data. In Figbifurcate or merge, the pattern of faults is especially ure 11 we present the same altimetric scan across one intricate.

In general, fracture belts deform mottled plains materials but not dark plains materials. The obvious diversion of flows and of channels in digitate flow fields ban around some fracture belts in eastern Lavinia (B in Figure 1) and the truncation of the fractures by flows indicate quite clearly that these fracture belts are older than the digitate flow fields.

A noteworthy aspect of a few of the fracture belts is that in some parts of them two distinct scales of deformation are observed. Faults are spaced very closely (typically a few hundred meters) almost everywhere Much of the faulting that is so prominent in the fracthey are present in fracture belts. However, in a few ture belts is similar in appearance, though much greater locales these closely spaced faults are concentrated in in density, to the faulting on the plains that forms the bands of intense deformation that are separated by grooves there. In fact, there are a number of instances nearly undeformed materials. The bands typically are (e.g., Figures 1 and 10 and Figure 17 below) where faultspaced $20-30 \mathrm{~km}$ apart. It was reported by Solomon et ing in fracture belts continues onto the plains, at much al. [1991] that these bands of intense deformation co- lower density, to form widely spaced grooves. As is the

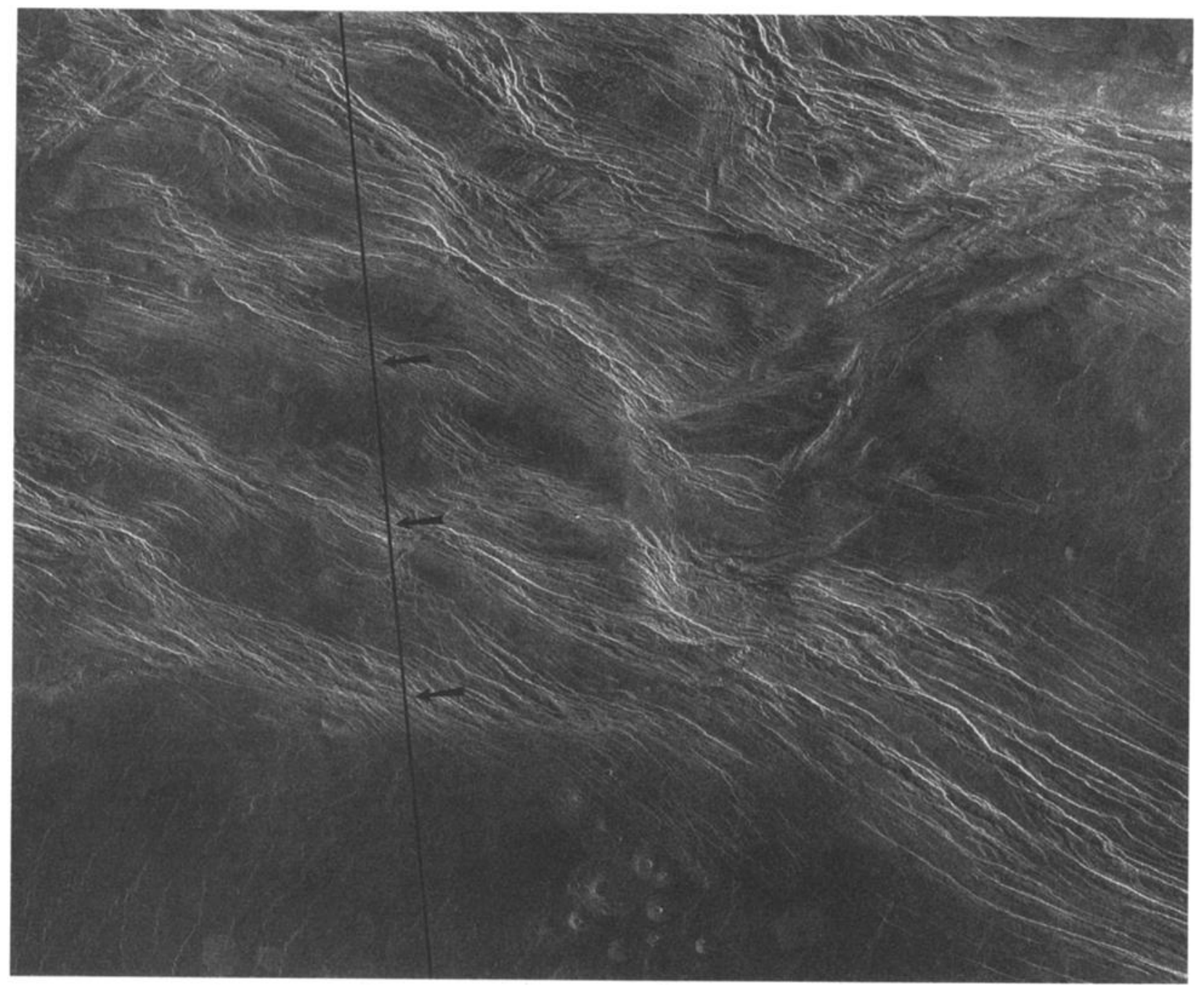

Fig. 10. A fracture belt. Width of the image is $260 \mathrm{~km}$. See Figure 1 for location. The altimeter ground track for orbit $\mathbf{4 1 5}$ is shown. Arrows correspond in position to arrows in Figure 11. 


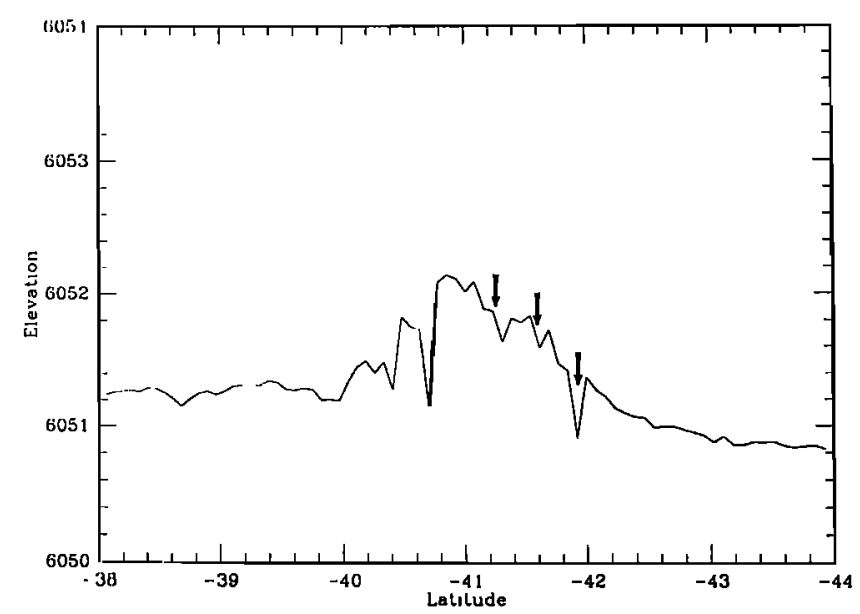

Fig. 11. Altimetry data from orbit 415. Arrows correspond in position to arrows in Figure 10.

case for the ridge belts and the wrinkle ridges, then, there appears to be a close relationship between faulting in fracture belts and the formation of grooves.

\section{Altimetry}

Magellan altimetry data have also provided the first detailed look at the topography of Lavinia Planitia. Figure 12 presents a topographic contour map for the Lavinia region. Overall, Lavinia is a broad, low plain, lying at a typical planetary radius of about $6050.5 \mathrm{~km}$. The regional topography rises gradually by more than $1 \mathrm{~km}$ to the northwest, northeast, and southeast. The general rise in elevation to the east continues well beyond the edge of our map and culminates in a line of several large coronae south of Alpha Regio [Stofan et al., this issue]. A prominent characteristic of the altimetry of Lavinia is that both types of deformation belts are elevated above the surrounding plains.

The fracture belts appear in general to reach higher elevations than the ridge belts. A number of the fracture belts reach elevations that are as much as $1 \mathrm{~km}$ above the level of the adjacent plains, and elevations $500 \mathrm{~m}$ above the plains within fracture belts are the norm. Particularly high elevations commonly are found in complex and intensely deformed regions present at bends and junctions in fracture belts. In contrast, maximum relief of $200-300 \mathrm{~m}$ is more typical for the ridge belts, and some of the ridge belts are not evident at all in the altimetric data. Some care must be exercised in interpretation of the altimetry, however, as determination of surface elevation for a given altimeter pulse can depend sensitively on both the large-scale and small-scale surface roughness within the pulse footprint. Roughness on a large scale can cause multiple echoes that severely complicate the range-finding algorithm. Roughness on a small scale can result in a surface scattering law that deviates from the one assumed in fitting the shape of the leading edge of an echo, again affecting the range-finding process. In any case where two terrains of significantly different roughness are observed, systematic variations in elevation between them must be treated with caution.

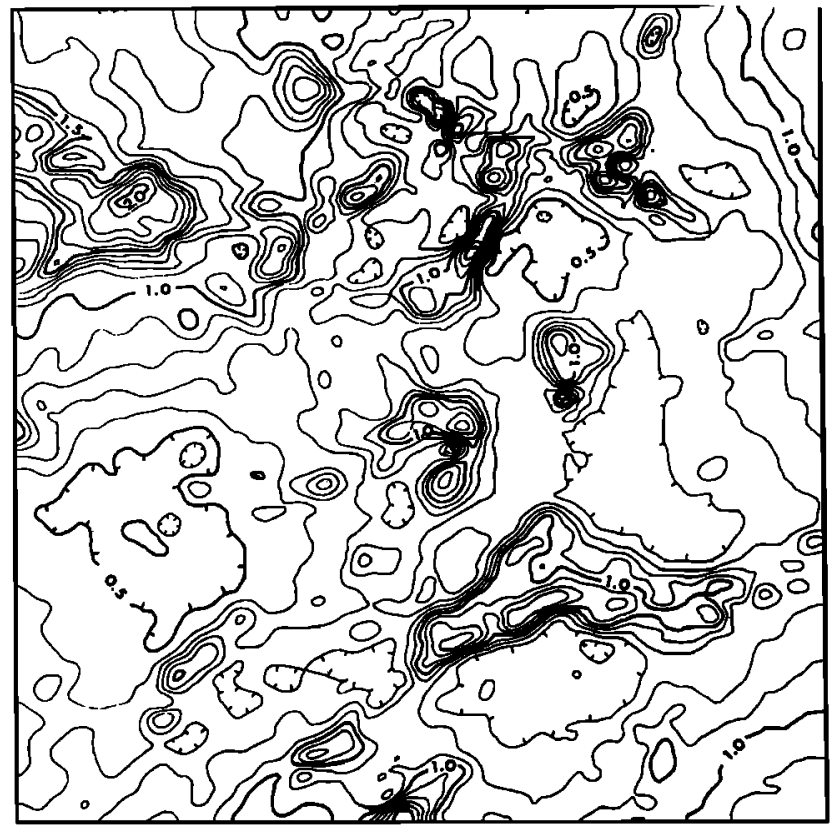

$$
\begin{aligned}
& \text { Lavinia: Contour Interval }=100 \mathrm{~m} \\
& \text { Latitude: } 44.25-50.9 \mathrm{~S} \\
& \text { Longitude: } 347.8 \mathrm{E}-356.9 \mathrm{E} \text { (at north edge) }
\end{aligned}
$$

Fig. 12. Topographic contour map for the area covered by Figure 1 , in sinusoidal equal-ares projection. Elevations are referenced to a planetary radius of $6050.0 \mathrm{~km}$.

\section{Geologic Relationships}

\section{Evidence for Horizontal Shear in Deformation Belts}

Solomon et al. [1991] presented two pieces of evidence for modest amounts of horizontal shear parallel to the axes of deformation belts. These are shown in Figures 8 and 10. In Figure 8, an old set of plains grooves exhibits an S-shaped bend consistent with distributed left-lateral shear as it crosses the ridge belt. In Figure 10, the fracture belt exhibits a number of instances where paired faults form rhombohedral downdrops, in a manner similar to what is seen in terrestrial settings where extension is coupled with shear. In this instance, the inferred sense of horizontal shear across the belt is right-lateral.

There are several other instances in Lavinia Planitia where patterns developed within deformation belts can be interpreted as very large-scale analogs of familiar kinematic indicators seen in terrestrial shear zones. One of these (Figure 13) shows a series of S-shaped minor folds along the lengths of individual ridges within a ridge belt. $S$ folds of this geometry are indicative of left-lateral (sinistral) movement and in this instance would imply sinistral shearing parallel to the length of the ridge belt. The belt showing the $S$ folds terminates to the SSW against a contact with mottled plains, and there is no indication of sinistral slip within these plains. Consequently, the inferred belt-parallel sinistral slip must be older than the mottled plains. It either represents a late stage in the development of the ridge belt or implies that the ridge belt is transpressional (com- 


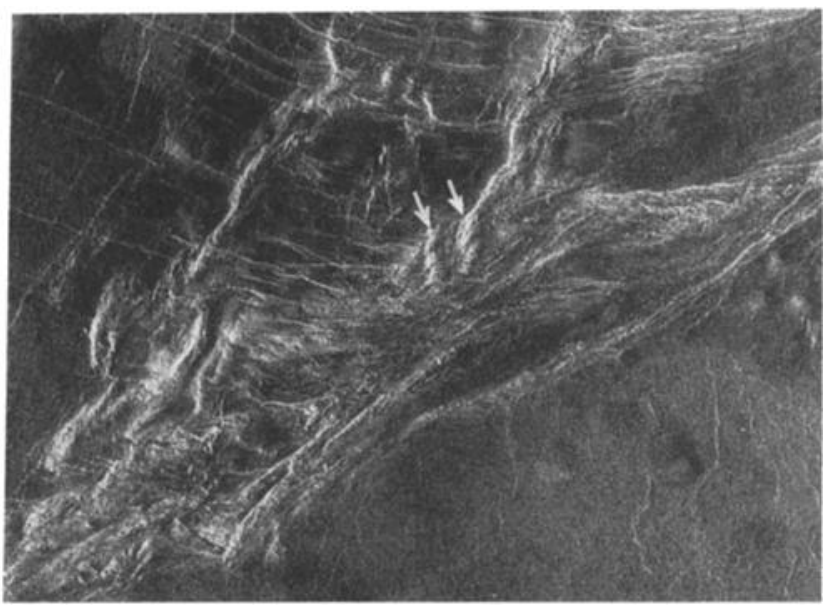

Fig. 13. S-shaped folds in a ridge belt, with orientations consistent with left-lateral shearing of the belt. Width of the image is $120 \mathrm{~km}$. See Figure 1 for location.

pression plus sinistral shear) rather than purely compressional in origin.

A second example of a possible kinematic indicator (Figure 14) involves the distortion of well-developed penetrative fabric in textured terrain as the fabric impinges on a throughgoing, strongly lineated boundary of a ridge belt. This boundary abrutly truncates all structures within the belt and is interpreted to be a shear zone. If this inference is correct, the distortion of the fabric at this location implies a right-lateral (dextral) sense of shear.

\section{Age Relationships Among Belts}

The deformation belts in Lavinia did not all form contemporaneously. Instead, they show some significant variability in age, both with respect to the plains materials surrounding them and with respect to one another. As noted above, a number of belts, particularly in western Lavinia, appear to deform the same material that constitutes the adjacent plains, with little or no subsequent volcanism. In the ridge belts, the transition from dark or mottled plains adjacent to the belt to the textured terrain of the belt is not necessarily a stratigraphic one in all cases; we cannot rule out the possibility that in some instances the texturing simply resulted from the folding of the plains material. However, there are other very clear instances where belts are embayed and partially buried by lavas that postdate the belt deformation. The N-S fracture belt at $\mathrm{C}$ in Figure 1 is one of these, and it may have once been contiguous with another aligned and partially buried N-S belt at $\mathrm{C}^{\prime}$.

An example of a clear crosscutting relationship involving two belts is shown at $D$ in Figure 1 . Here a N-S belt has been largely buried by lavas, and these lavas have in turn been deformed to form an E-W belt that crosscuts the N-S one. This case in particular demonstrates that belt formation in Lavinia took place over an extended period of time, during which which belt formation episodes were interleaved with plains volcanic events.

\section{Regional Tectonic Trends}

As noted above, there are two classes of deformation

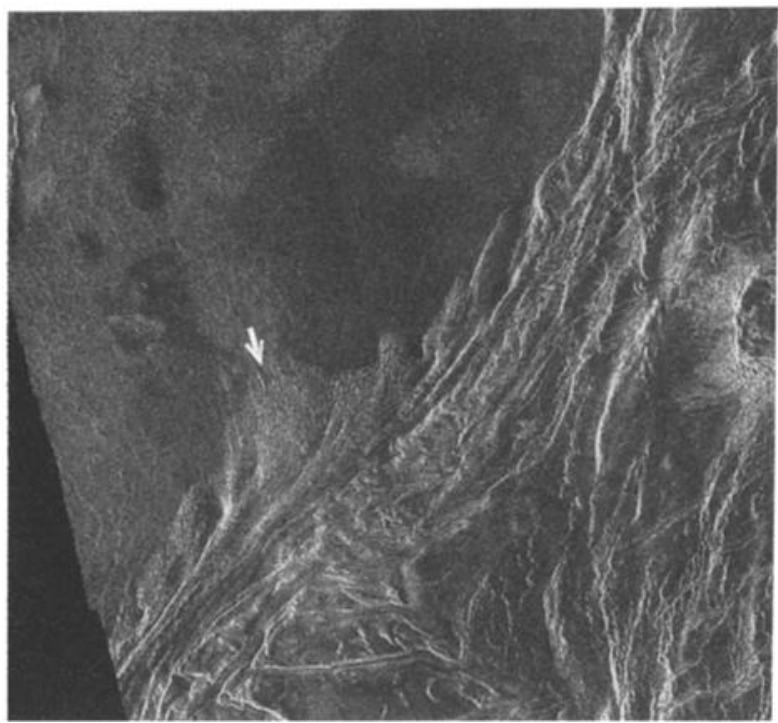

Fig. 14. Penetrative fabric in textured terrain that is distorted with a geometry consistent with right-lateral shear across a ridge belt. Width of the image is $125 \mathrm{~km}$. See Figure 1 for location.

belts in the Lavinia region, and each appears related to tectonic features on the intervening plains. Specifically, ridges of the ridge belts are morphologically similar to and in some cases contiguous with plains wrinkle ridges, and faults of the fracture belts are similar to and in some cases contiguous with plains grooves. In some parts of Lavinia, however, these relationships may be more fundamental, as suggested by Figures 5 and 7 . The morphologic form taken by each deformation belt, ridge belt or fracture belt, appears related in many instances to the orientation of the belt with respect to the orthogonal tectonic features on the adjacent plains. Belts whose orientations are closest to those of the plains grooves in their vicinity tend to be fracture belts, while those whose orientations are closest to those of local wrinkle ridges tend to be ridge belts. Even more notably, there are instances, as in Figure 15, where a single belt changes from one trend to the other, and in so doing also changes tectonic style from one belt type to the other. In addition, there are some belts (e.g., Figure 16) where both ridges and fractures are common within the belt and where the ridges lie parallel to local plains wrinkle ridges and the fractures lie orthogonal to them and parallel to local plains grooves.

There are exceptions to this relationship. The most obvious one is the N-S fracture belt at $\mathrm{C}$ in Figure 1 . In this same belt, some ridges also are present and lie parallel to fractures, rather than perpendicular to them. Other belts departing from the general relationship occur farther to the east. Despite these exceptions, the relationship described above appears sufficiently prevalent, particularly in western Lavinia, that it must be accounted for in some fashion. The belts in central and eastern Lavinia that deviate from the general pattern are in most cases very clearly buried and embayed by younger volcanic deposits and perhaps are formed in a stress field distinct from the one responsible for most of the wrinkle ridges and grooves. 


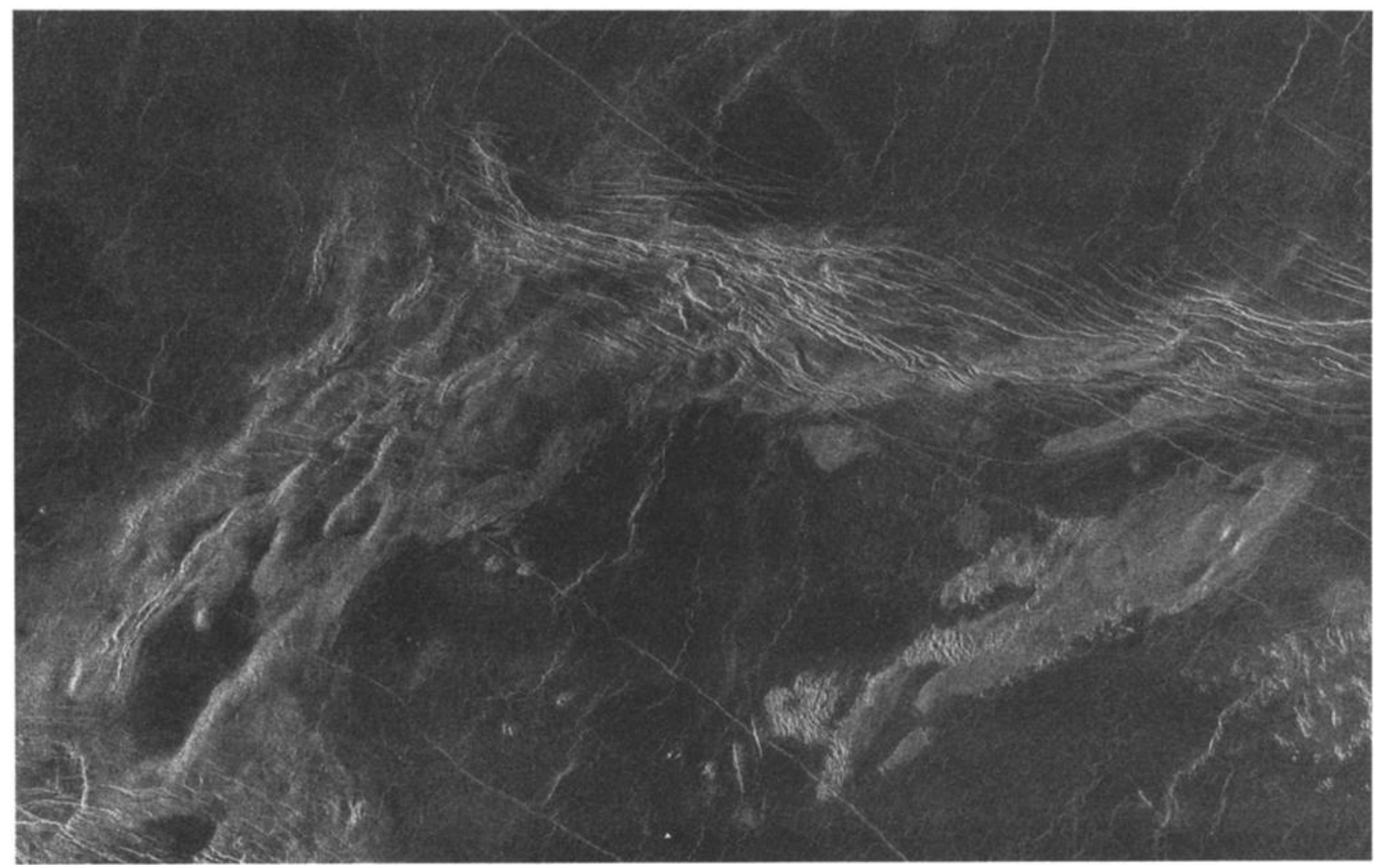

Fig. 15. A deformation belt that changes from a ridge belt to a tracture belt along its length. Width of the image is $290 \mathrm{~km}$. See Figure 1 for location.

\section{Discussion}

\section{Geologic Evolution of Lavinia Planitia}

The description above of geologic units and tectonic features in Lavinia Planitia leads us to some preliminary interpretations:

Regional tectonic pattern on the plains. The orthogonal pattern of compressional wrinkle ridges and extensional grooves that transects the plains units over much of Lavinia Planitia is remarkable in its regularity and in both its spatial and temporal extent. These characteristics indicate that at least the near-surface materials of Lavinia have been subjected to a stress field that has been generally uniform, both spatially and temporally, for much of the region's history. This conclusion is not unique to Lavinia, since a variety of regular tectonic patterns are observed on the plains elsewhere on the planet [Solomon et al., 1991, this issue].

It is tempting to think of the wrinkle ridges and grooves on the plains as the simple manifestations of thrust faulting and normal faulting, respectively, and this interpretation may well be correct. If so, it has some interesting implications. A common approach to predicting faulting style from stress field descriptions is that of Anderson [1951]. With the Anderson faulting criteria, however, no single set of values of the three principal stresses $\sigma_{1}, \sigma_{2}$, and $\sigma_{3}$ simultaneously predicts orthogonal grabens and thrust faults. Applying Anderson criteria rigorously, one can obtain either thrust faults or grabens from a given stress field orientation, but not both.

Orthogonal thrust faults and grabens may both be formed, according to Anderson criteria, if the two stress components in the plane of the surface maintain their relative values but vary appropriately with respect to the vertical stress. One way this could take place would be for the in-plane stresses to vary relative to the vertical stress over time. Another would be if fault initiation for the two classes of features took place at different depths [Golombek, 1985], near the surface for thrust faults and at depth for grabens, so that in the former case the vertical stress is $\sigma_{3}$ and in the latter case it is $\sigma_{1}$. (The depth is limited, however, since many grabens are very narrow.)

In either of these scenarios there is a stress state, intermediate in either time or depth, for which Anderson criteria would predict strike-slip faulting. Clear evidence for strike-slip faulting is rare on Venus (and indeed on most of the terrestrial planets save Earth), and is lacking entirely on the plains of Lavinia. One explanation offered for the absence of strike-slip motion on other planets is that layered mechanical discontinuities concentrate stress, and hence fault initiation, at certain depths (and hence at certain confining stresses) where faults with styles other than strike-slip tend to be initiated [Golombek, 1985]. Another possibility is simply physical restriction of lateral movement. A planet has 


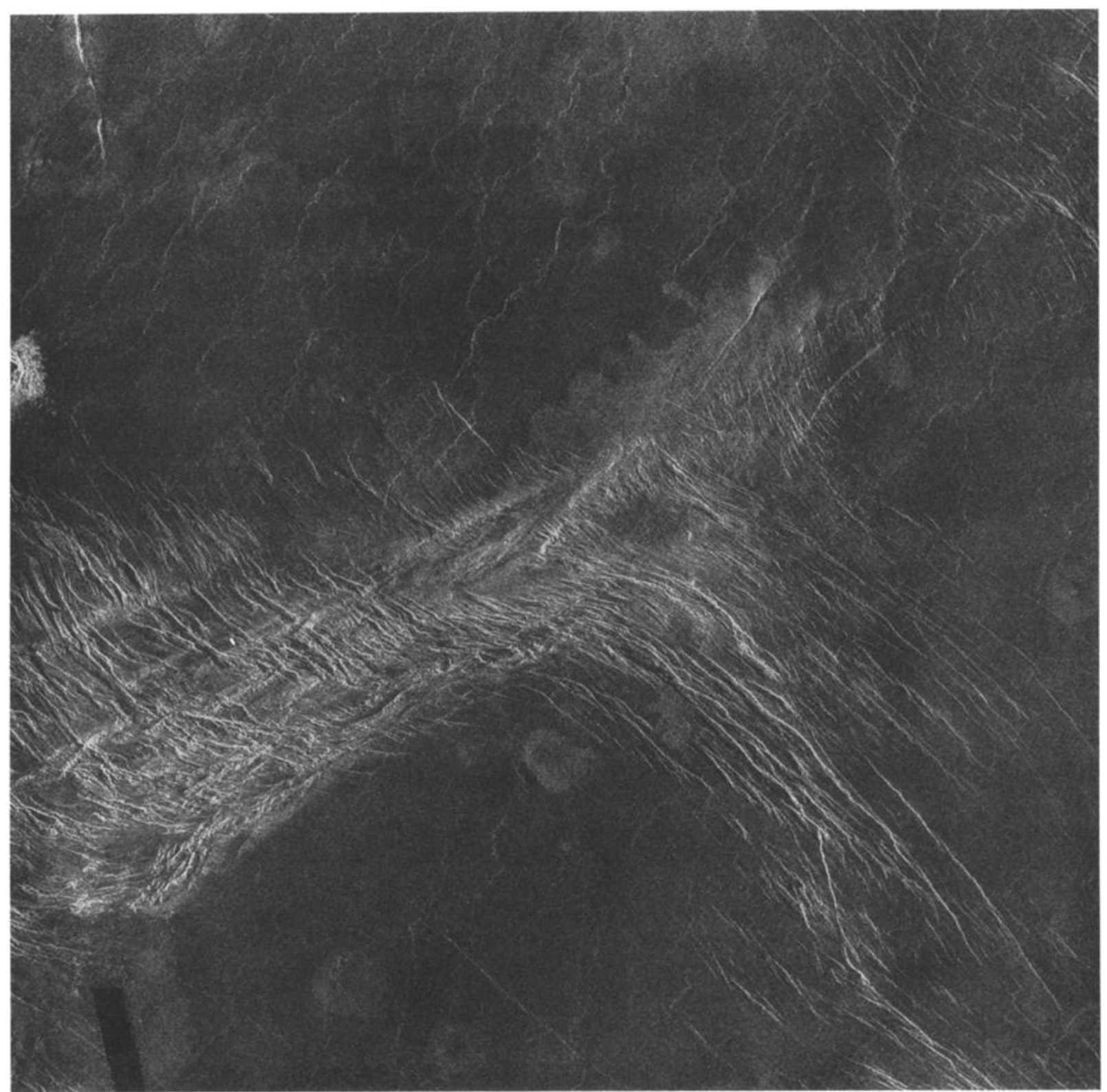

Fig. 16. A deformation belt that exhibits both ridges and fractures, with approximately orthogonal orientations. Width of the image is $240 \mathrm{~km}$. See Figure 1 for location.

a free surface and a ductile region at depth, so thrust and normal faulting within the strong upper crust can always be accommodated by vertical motions, and the stress at the base of a fault cutting the entire strong upper layer can relax by ductile flow. On a one-plate planet or within the interior of a single lithospheric plate, however, there may be restrictions on the extent of horizontal strain, and stress relaxation at the ends of strike-slip faults will not be comparable to that for dipslip faults. It may be that such restrictions inhibit most large-scale (i.e., easily observed) strike-slip motions in Lavinia. Schultz and Zuber [1991] have recently suggested that in situations where the lithosphere is vertically loaded, tensile failure rather than shear failure may relieve much of the stress and may suppress the zone in which shear failure criteria predict strike-slip faulting.
Deformation belts. In contrast to pre-Magellan expectations, we now know that there are two distinct classes of deformation belts (ridge belts and fracture belts) in Lavinia. A particularly important question is whether or the not ridge belts and fracture belts both owe their origin to a similar mechanism. Evidence suggesting that they do includes geometric similarities between the two classes of belts (widths, positive topographic signatures, patterns traced across the plains) and, particularly, the observation that a few belts undergo a transformation from ridge morphology to fracture morphology along their length. Similar changes in morphology along the length of a belt occur in the deformation belts of Atalanta Planitia as well [Solomon et al., this issue]. It is clear, however, that whatever the underlying cause of belt formation, the surface tectonic 
expressions of ridge and fracture belts are markedly different.

Because of the gross similarities of both types of belts, and particularly because both are elevated, one reasonable working hypothesis is that both result from belt-normal crustal shortening and thickening [Solomon et al., 1991]. In the case of the ridge belts, this argument is straightforward: the ridges are interpreted to be folds formed by ridge-normal compression. In the case of the fracture belts, however, the argument is really based only on the altimetry. All of the belts lie higher than the surrounding plains and hence are attributed in this interpretation to a thickening, via belt-normal shortening, of the buoyant crust.

A difficulty with the idea that both types of belts share a common origin is that the most straightforward interpretation of the observed tectonic features in the fracture belts runs directly counter to this interpretation. While near-surface materials in the ridge belts have been deformed to produce folds, the same materials in fracture belts are intensely faulted in what appears to be a manifestation of near-surface extension. One could interpret these belts, then, as being wholly extensional features, with the uplift a consequence of lithospheric heating or igneous intrusion. Alternatively, in the compressional interpretation, the observed faulting could be the consequence of stretching of brittle surface materials across the crest of an archlike uplift whose underlying origin is compressional. The strongest argument that both belt types owe their origin to the same process may be that single belts exist that exhibit both morphologies, depending on their local trend.

While the great extent and uniformity of the orthogonal tectonic pattern of Lavinia indicate that the nearsurface materials there have been subjected to a stress field of significant spatial and temporal regularity, the deformation belts of Lavinia, in contrast, are geometrically very irregular and can change trend substantially along their length, bifurcating and merging to form an intricate pattern. If there is a single underlying belt formation process, then the irregular orientations of the belts with respect to the orthogonal pattern of the plains suggest that this process is not related in a simple manner to the one responsible for the near-surface stresses expressed on the plains. The morphologic manifestation of each belt nonetheless commonly depends on the orientation of the belt with respect to the tectonic pattern of the plains: ridge belts form where the belt is perpendicular to the regional compressive stress, and fracture belts form where the belt is perpendicular to the regional extensional stress. In both cases there apparently can be some distributed shear across the belt, as indeed is likely to be the case when the belt axis is not perfectly orthogonal to any principal stress.

The source of stress responsible for formation of the deformation belts of Lavinia is not known, but mantle convection must be considered the prime candidate. It has been suggested that the Venusian mantle may lack an Earth-like asthenosphere [e.g., Phillips, 1990]. If this is the case, convective stresses can couple strongly to the lithosphere and can lead to deformation of the lithosphere at wavelengths comparable to the spacing of the Lavinia deformation belts [Zuber, 1987, 1990].
The surface manifestation of convective stresses, however, will also depend on the rheologic structure of the crust. A model in common use for crustal and upper mantle rheology on Venus involves a crust of basaltic composition overlying an olivine-rich mantle. This configuration can lead to a layered rheologic structure, with a strong upper crust, a ductile lower crust, a strong upper mantle, and ductile mantle material below [Zuber, 1987; Banerdt and Golombek, 1988]. A weak lower crust may be relatively ineffective in transmitting convective stresses to the upper crust.

We cannot presently answer the question of whether the mantle motions and resultant stresses that led to formation of the two classes of belts in the Lavinia region were fundamentally the same. In some respects the interpretation of the data is more straightforward if they were not, since the surface morphologic expressions of the two belt types are quite different. However, we have already noted the arguments for the view that both belt types share a common underlying origin, and these arguments appear fairly persuasive. Because the pattern of the belts is so complex, stresses produced in the strong upper mantle by convection must also have been complex, both spatially and temporally. The stresses that produced surface deformation on the plains, however, must have been spatially and temporally quite regular. The surface stress field must therefore have resulted from the superposition of (1) stresses generated by mantle convection and transmitted across the ductile lower crust with (2) stresses in the strong upper crust of unknown origin that were much more regular in space and time. The former stresses are expressed at the surface primarily by the elevated belts themselves. The latter stresses must have dominated the in-plane components of stress in near-surface materials, controlling both the orientation of the plains tectonic features and the style of deformation within the belts. A mixed stress field of this sort might be enabled by a ductile lower crust that incompletely transmits stresses from the upper mantle to the upper crust.

Our observations of the Lavinia region raise a number of questions:

1. What process is responsible for the stress field that produced the orthogonal tectonic pattern on the plains, both here and elsewhere on Venus?

2. What process is responsible for the stresses that produced the elevated deformation belts, and for the concentration of the deformation into discrete belts?

3. What do the dominant wavelengths of deformation, both within and among the belts, indicate about the mechanical properties of the venusian crust and mantle?

4. If the two classes of belts share a common origin, is there a fully self-consistent stress distribution and history that can produce the deformation observed?

5. If the two classes of belts have fundamentally different origins, why are they so similar in some respects? Why are there belts with both characteristics, and especially belts that change style along their length? Why are the fracture belts different from rift zones elsewhere on the planet?

In the two sections that follow, we make a first attempt to address questions 2 and 3 above. The others 
will be left for consideration in future work.

\section{Dynamical Models for Belt Formation}

We have argued above that the large-scale morphology of deformation belts, and of the ridge belts in particular, may be consistent with the hypothesis that these features are products of lithospheric shortening and crustal thickening. This was also the conclusion reached by most investigators prior to the Magellan mission, and previous workers have postulated this shortening to be the result of convective downwelling centered beneath lowlands regions [Zuber, 1990; Bindschadler et al., 1990; Phillips et al., 1991]. In this section we use finite element models to investigate quantitatively the relationship between mantle convection and crustal deformation, with particular emphasis on the conditions favoring the formation of deformation belts.

The geometry and characteristic spacing of the deformation belts of Atalanta Planitia suggest that these features result from lithospheric instabilities induced by horizontal extensional or compressional stress [ $Z u$ ber, 1987]. There are two characteristic scales of deformation associated with these belts: one describing the spacing of features (e.g., ridges) within the belts, and one describing the spacing of the belts themselves.
Linear stability analysis indicates that two scales of deformation can arise given sufficient compression or extension if the lithosphere is rheologically stratified, i.e., if a weak lower crustal layer is sandwiched between a relatively strong upper mantle and a strong upper crust. A stress-dependent rheology is required for the instabilities to grow. Zuber [1990] suggests that the compressional stresses required to induce the instabilities may be supplied by mantle convection. This hypothesis requires that the stresses associated with the motions of the mantle couple into the overlying crust. The high correlation of long-wavelength topography and gravity and the large apparent depths of compensation suggest that Venus lacks an upper-mantle low-viscosity zone [Kiefer et al., 1986; Bills et al., 1987; Phillips et al., 1991; Smrekar and Phillips, 1991]. If so, then mantle convection should indeed couple strongly to the lithosphere, and patterns of mantle flow should have recognizable signatures in surface topography and deformation [Phillips, 1986, 1990].

On the basis of analytical models of convectioninduced crustal flow [e.g., Bindschadler and Parmentier, 1990; Schmeling and Marquart, 1990], the crust may be regarded as having two responses to convective

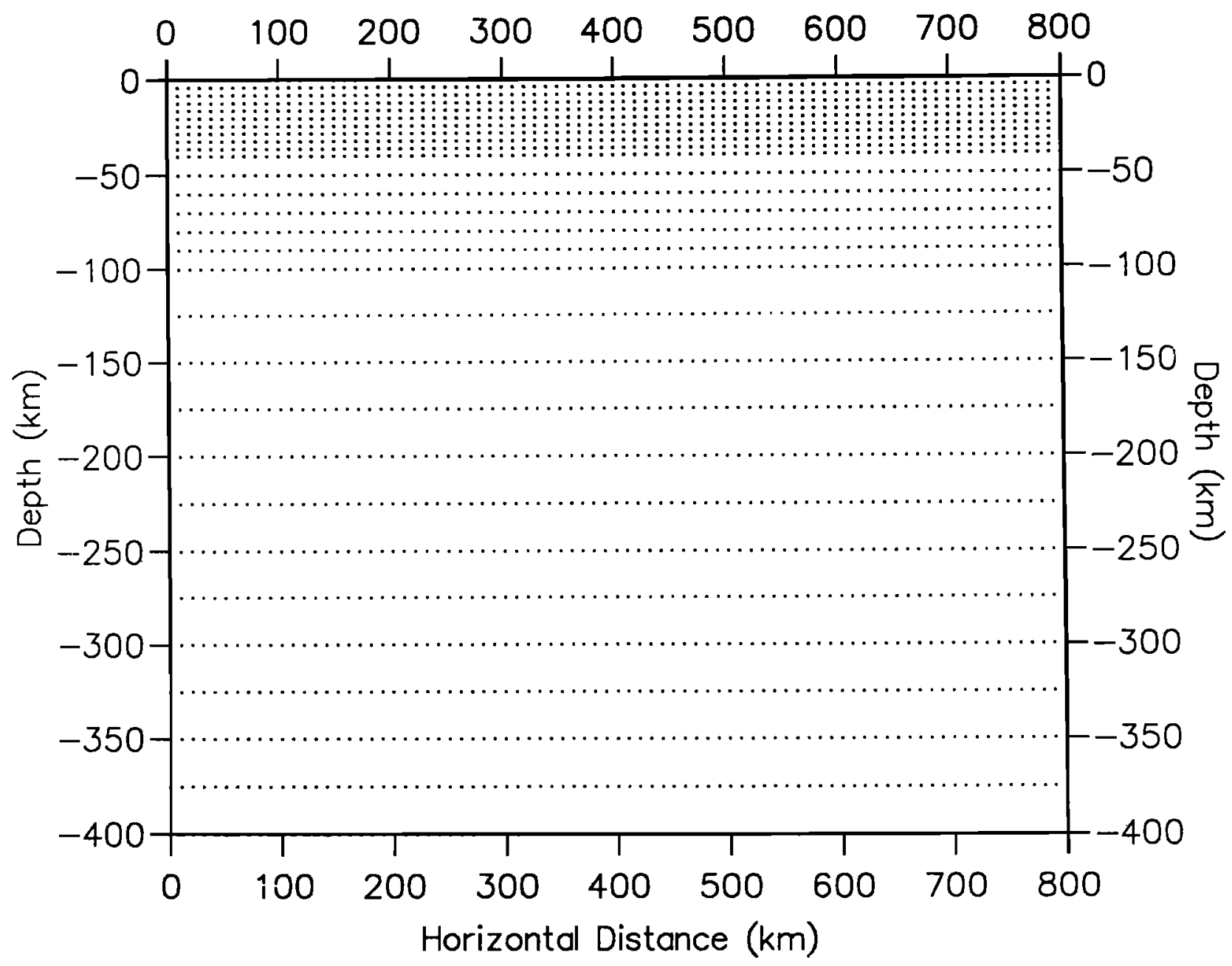

Fig. 17. The finite element mesh used for calculations of convectively induced deformation of the crust. The mesh is 28 by 80 elements with a highest vertical resolution of $4 \mathrm{~km}$ in the upper $40 \mathrm{~km}$. 
downwelling. The first is a "flexural" response, during which the surface and crust-mantle boundary can be thought of as deforming "in phase." Following this mode of deformation, the crust responds by thickening, and eventually the surface and the crust-mantle boundary become anticorrelated.

Simons et al. [1991] have proposed that deformation belts like the ones observed in Lavinia Planitia can form during the transition from the initial flexural response to the later phase of crustal thickening, and we expand on this suggestion here. We illustrate this proposal by means of idealized finite-element models of the dynamic interaction between the crust and mantle. The crust and mantle in these models are treated as viscous fluids, and a modified version of the twodimensional Cartesian finite-element program ConMan [King et al., 1990] is employed. A passive marker chain tracks the crust-mantle interface and permits variation in the crustal buoyancy as well as specification of different crustal and mantle rheologies. In addition to the flow field, the stress field in the lithosphere and the surface topography are readily calculated.

We use an irregular finite element mesh that is 28 elements high and 80 elements wide (Figure 17). Our maximum resolution is in the $40-\mathrm{km}$-thick top layer, where each element is $4 \mathrm{~km}$ high and $10 \mathrm{~km}$ wide. In all, the mesh is $800 \mathrm{~km}$ in the horizontal dimension and $400 \mathrm{~km}$ in the vertical dimension. We impose free-slip boundary conditions on the top and side walls, with no flow through these walls. On the bottom boundary, flow is constrained to be vertical, with no deviatoric normal stress permitted. In effect, this last boundary condition gives us a virtual $800 \mathrm{~km}$ by $800 \mathrm{~km}$ box. The surface topography is calculated from the vertical stresses on the top wall of the box. Top and bottom temperatures are fixed at $500^{\circ} \mathrm{C}$ and $1250^{\circ} \mathrm{C}$, respectively. Initially, we impose a linear temperature gradient across the thermal boundary layer and set the rest of the mantle to be nearly isothermal with a small sinusoidal temperature perturbation imposed throughout the box to initiate flow.

Our exploratory models have a constant viscosity mantle overlain by a crust of greater constant viscosity. As noted above, the viscosity in the actual Venusian crust and mantle is likely to vary with depth; in these simple models the higher viscosity crust is intended to represent a strong surface layer capable of being deformed by stresses induced by mantle convective motions. We adopt a reference mantle viscosity of $10^{21}$ $\mathrm{Pa} \mathrm{s}$, a crustal density of $3000 \mathrm{~kg} \mathrm{~m}^{-3}$, and a mantle density of $3300 \mathrm{~kg} \mathrm{~m}^{-3}$. We use initial crustal thicknesses of 12 and $25 \mathrm{~km}$, and ratios of crustal viscosity to mantle viscosity of 25,50 , and 100 . In all these models, convection produces horizontal compressive stresses in the lithosphere that overlies downwelling mantle and extensional stresses in the lithosphere that overlies upwelling mantle. As the convective vigor increases, so does the magnitude of the compressive stress over the downwelling, with stress in the crust reaching values in excess of $100 \mathrm{MPa}$ in about $100 \mathrm{~m} . \mathrm{y}$. (Figure 18). Note that the rate of increase in compressive stress decreases with increasing crustal viscosity. This is because the stronger the crust, the more the development of the

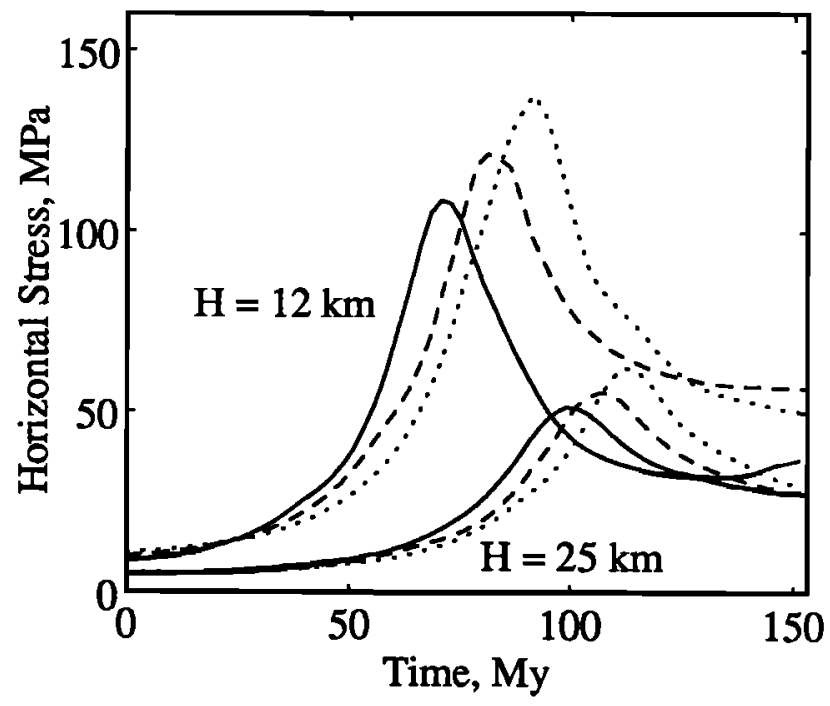

Fig. 18. Development of horizontal compressive stress versus time in models of convectively induced crustal deformation. Stress is measured at the top right-hand (downwelling) side of the model. Models shown include crust/mantle viscosity ratios of 25 (solid line), 50 (dashed line), and 100 (dotted line), and a crustal thickness $H$ of 12 or $25 \mathrm{~km}$. Note the similarities among the curves and the peak in compressional stress.

convective instability in the mantle driving the deformation is impeded. We also find that the magnitude of the peak compressive stress achieved above the downwelling increases with higher viscosities and/or with thinner initial crustal layers; the stronger the crustal lid, the larger the tractions from mantle convection supported by the crust. Since force balance on the crust requires that shear traction integrated along the base be balanced by normal stresses integrated through its thickness, the thinner the crust, the larger the horizontal stresses.

The topography over the downwelling undergoes a complex evolution in these models (Figure 19). Initially, the effect of stresses induced by downgoing mantle dominates, producing topographic lows. After reaching a minimum, the topography grows due to the isostatic contribution from the thickened crust. We suggest that if the deformation belts are the result of compressive stress and that mantle convection is the source of this stress, then the belts will develop at or before the time of maximum horizontal compressive stress. This time corresponds to the transition from decreasing to increasing topography.

Theory derived by Biot [1961] shows that horizontal compression of a buoyant viscous plate overlying a viscous substratum will have a dominant wavelength that depends on the difference in layer densities $\Delta \rho$, the ratio of viscosities $\eta_{c} / \eta_{m}$, the applied stress $P$, and the layer thickness $H_{c}$. For values of the quantity $P /\left(\Delta \rho g H_{c}\right)$ less than about 7 , the amplification of folds becomes insignificant. For one of our models described above, with $\eta_{c} / \eta_{m}=100, H_{c}=12 \mathrm{~km}, \Delta \rho=300 \mathrm{~kg} / \mathrm{m}^{3}$, and $P=100 \mathrm{MPa}$, the dominant wavelength is about 100 $\mathrm{km}$. However, these parameters are near the threshold conditions for significant fold amplitudes.

Our initial results show that coupling of convective motions to the lithosphere will cause significant crustal 

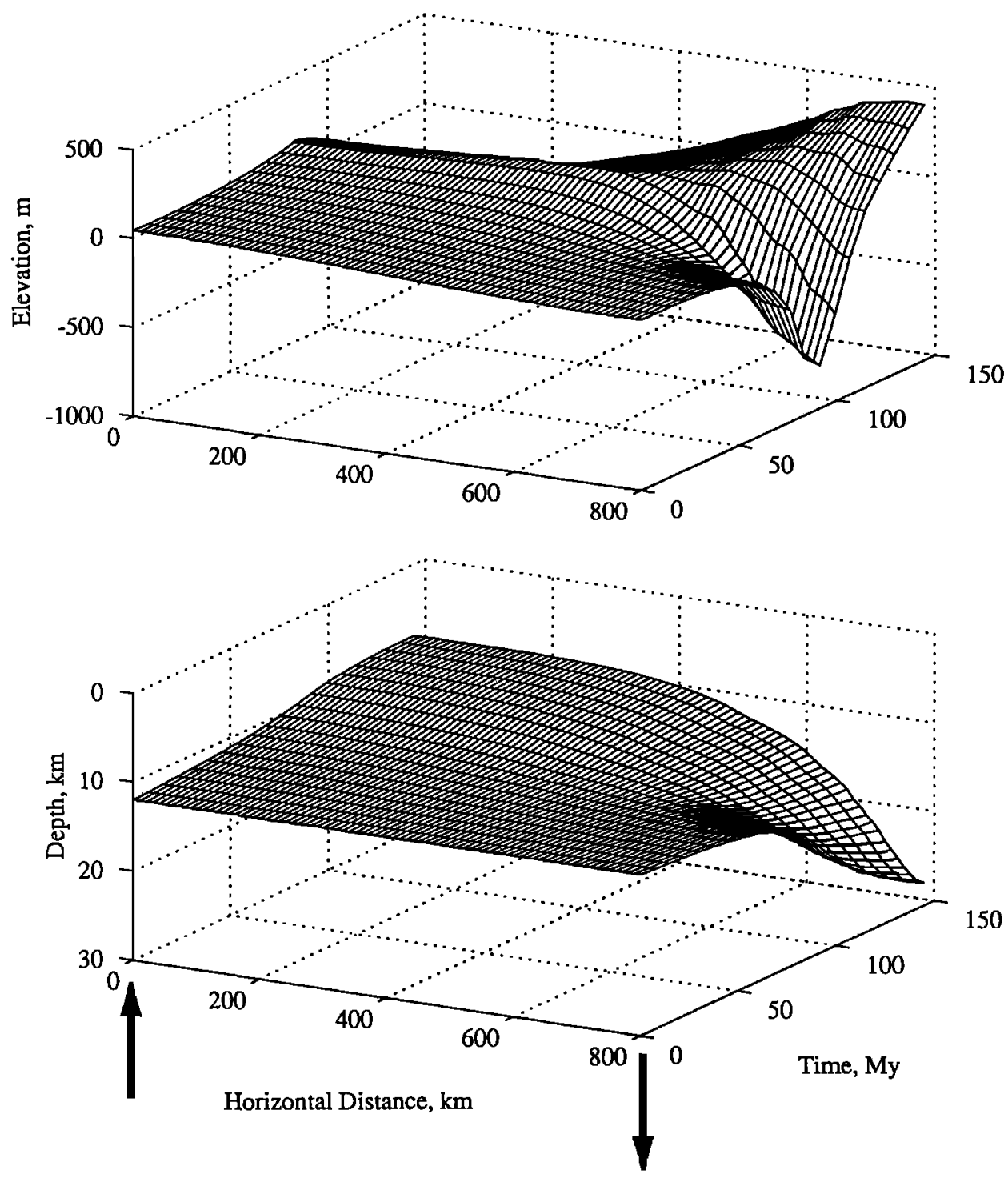

Fig. 19. Evolution of surface elevation (top) and the depth to the crust-mantle interface (bottom) with time for a model of crustal deformation induced by mantle convection. Note the initial decrease in elevation over the zone of downwelling (downward arrow), followed by an eventual increase in elevation. Note also the steady increase in crustal thickness over the zone of downwelling. The initial crustal thickness, $H_{c}$, is $12 \mathrm{~km}$, and the ratio of crustal viscosity to mantle viscosity is 70 .

deformation. This deformation is complex and highly time dependent. Our results are preliminary, and modeling with more realistic rheologies is in progress. However, the simple rheologies assumed here are sufficient to generate stress fields that, together with simple theory $[B i o t, 1961]$, predict the predominant wavelength of deformation seen in Lavinia Planitia. This theory may also explain why the belts are only generated for a finite period of time before they become overwhelmed by larger-scale deformation.

\section{Buckling Within Individual Ridge Belts}

We have argued that the ridge belts observed on Lavinia Planitia are fold belts, formed by buckling of a strong upper crust in response to ridge-normal compression. If this interpretation is correct, then we may use observations of ridge geometry, along with a simple mechanical model of buckling, to place some quantitative constraints on the structure of Venus's crust at the time of ridge formation. We model the ridges here as having formed due to a buckling instability in an elastic layer with a depth-dependent yield strength subjected to a compressive end force. Our general approach follows that of Banerdt and Golombek [1988]. We consider the strength of the venusian lithosphere to be determined by two deformation mechanisms: brittle failure and ductile flow [see Brace and Kohlstedt, 1980]. At a given depth, the local pressure and temperature determine the yield stress for each mechanism; the lithospheric strength is taken to be the weaker of the two.

In our modeling, the critical differential stress for brittle failure is taken to be $\tau=\mu \sigma_{n}$ [Byerlee, 1978], where $\tau$ and $\sigma_{n}$ are the shear and normal stresses, respectively, and $\mu$ is the coefficient of friction. The critical differential stress for ductile flow is derived from the 
creep equation $\dot{\epsilon}=A \sigma^{n} \exp (-Q / R T)$, where $\dot{\epsilon}$ is the strain rate, $\sigma$ is the differential stress, $R$ is the gas constant, $T$ is the absolute temperature, and $Q$ and $n$ are experimentally determined constants. We take values for these constants appropriate for dry diabase [Caristan, 1982].

An example of a lithospheric strength profile for horizontal compression calculated from the above models is given by the heavy solid line in Figure 20. The strength increases linearly with depth near the surface (in the brittle regime) due to the increasing lithostatic stress and then decreases exponentially (in the ductile regime) due to the thermal gradient. For this figure we use a surface temperature of $720 \mathrm{~K}$, a thermal gradient (assumed constant) of $15 \mathrm{~K} \mathrm{~km}^{-1}$, and a strain rate of $10^{-15} \mathrm{~s}^{-1}$. Now, consider how the strength profile of Figure 20 responds to an applied stress of of $70 \mathrm{MPa}$ (the dashed vertical line in the figure). Only those depths with a lithospheric strength exceeding the applied stress (between $Z_{t}$ and $Z_{b}$ ) will support the entire stress load elastically. Depths above $Z_{t}$ will only support part of the load elastically (up to the yield stress) and will undergo brittle failure. Depths below $Z_{b}$ will only support part of the load and will undergo ductile creep.

At the crust-mantle boundary, a change in composition can create another rheologic transition. Mantle material on Venus has been assumed in most models to be olivine-rich in composition and hence to possess much higher yield stresses than the crust, leading to another brittle-ductile failure envelope in the upper mantle [e.g., Zuber, 1987; Banerdt and Golombek, 1988]. In line with the calculations above, this deeper strong zone could be responsible for longer wavelengths of deformation on Venus. Here we only consider short-wavelength folding and take it to be a function only of the crustal

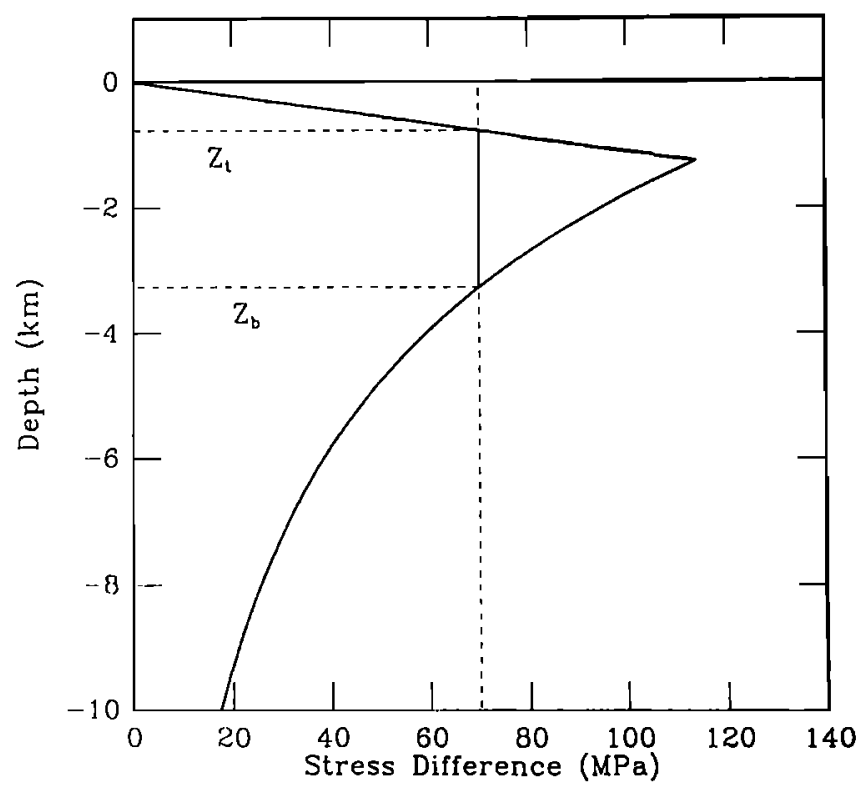

Fig. 20. A typical strength envelope for the venusian crust, showing strength as a function of depth, with an upper regime controlled by frictional failure on faults and a lower regime controlled by ductile flow. Calculations are for a dry diabase rheology, a surface temperature of $720 \mathrm{~K}$, a thermal gradient of $15 \mathrm{~K} \mathrm{~km}^{-1}$, and a strain rate of $10^{-15} \mathrm{~B}^{-1}$. failure envelope, neglecting the potential influence that the coupling between the crust and mantle discussed in the previous section could have on the stress field.

An elastic plate overlying an inviscid fluid will buckle if subjected to a sufficiently large compressive end load. The critical force required is given by [Turcotte and Schubert, 1982, p. 124]

$$
F_{c}=\left[\frac{E h^{3} \rho g}{3\left(1-\nu^{2}\right)}\right]^{1 / 2},
$$

where $E, h$, and $\nu$ are the Young's modulus, thickness, and Poisson's ratio of the plate, respectively, $\rho$ is the fluid density, and $g$ is the gravitational acceleration. Given this force, the elastic plate will deform with a characteristic wavelength

$$
\lambda=2 \pi\left[\frac{E h^{3}}{12\left(1-\nu^{2}\right) \rho g}\right]^{1 / 4} .
$$

This simple buckling model was adapted by McAdoo and Sandwell [1985] to the more complicated case for which the elastic plate possesses a brittle-ductile strength envelope as discussed above. They found that equations (1) and (2) hold quite well if the plate thickness is set equal to the thickness of the "elastic core", defined as the region for which the strength of the lithosphere excedes the applied stress (i.e., the thickness of the region between $Z_{t}$ and $Z_{b}$ in Figure 20). This approach avoids the unreasonably high critical buckling stresses found when finite strength envelope is ignored. The critical load for this model is determined by equating the left side of equation (1), now taken as an integral over the entire thickness of the crust of the supported stress, to the right side of equation (1), with the elastic core thickness set as the effective plate thickness. Since both sides of the equation depend upon the applied stress, the critical load and corresponding buckling wavelength must be solved iteratively. In all of our calculations, the derived critical buckling stress is smaller than the maximum lithospheric strength; therefore an elastic core exists and buckling occurs before complete lithospheric failure.

The dominant wavelength of folding determined by the above model depends on three parameters: the crustal thickness, the thermal gradient, and the strain rate. Figure 21 shows contour plots of the dominant wavelength of folding, in kilometers, as a function of these parameters. In each plot, one parameter is held constant. Figure $21 a$ assumes a thermal gradient of 25 $\mathrm{K} \mathrm{km}^{-1}$; Figure $21 b$ assumes a strain rale of $10^{-16} \mathrm{~s}^{-1}$; Figure $21 c$ assumes a crustal thickness of $10 \mathrm{~km}$. All results are calculated assuming a surface temperature of $720 \mathrm{~K}$, a density for the ductile lower crust of 2800 $\mathrm{kg} \mathrm{m}^{-3}$, a Young's modulus of $100 \mathrm{GPa}$, and a Poisson's ratio of 0.25 .

Figure 21 shows that the folding wavelength is not very sensitive to the crustal thickness, particularly for thicknesses greater than about $10 \mathrm{~km}$. This is a result of the rapid dropoff in lithospheric strength (see Figure 
20) due to ductile creep. The bottom of a thick crust contributes very little strength to the crust, and therefore has comparatively little influence on the folding mechanics. As the crustal thickness decreases, the folding wavelength shows more and more of a dependence, with the thinnest crust yielding the shortest wavelengths. Of course, the development of a second, longer wavelength of deformation does depend strongly on crustal thickness [Zuber, 1987, 1990].

The thermal gradient and strain rate both can have a significant effect on the folding wavelength. Increasing the thermal gradient decreases the wavelength, while increasing the strain rate increases the wavelength. Of course, as Figure 21c demonstrates, the folding wavelength can remain essentially constant as the combination of a relatively large strain rate and thermal gradient is varied to a relatively small strain rate and thermal gradient. This behavior is a consequence of the form of the creep law for the ductile deformation. Increasing the thermal gradient and decreasing the strain rate both lower the ductile yield stress of the crust, thinning the lithosphere and decreasing the resulting folding wavelength.
In Figure $21 d$, we have set the folding wavelength to $8 \mathrm{~km}$, a value representative of ridge spacing in the ridge belts of Lavinia Planitia. This allows us to vary all three of the key model parameters simultaneously. The contours show the thermal gradient required, in kelvins per kilometer, to produce folding with a wavelength of $8 \mathrm{~km}$, as a function of strain rate and crustal thickness. Ultimately, we would like to be able to use this plot to constrain the thermal gradient in Lavinia at the time of deformation. In order to do this, however, we need to know the strain rate involved in ridge belt formation. Given the geometry of the belts and typical estimates of the age of the Venusian surface, a strain rate corresponding to $10 \%$ shortening per 100 m.y. is probably an extreme lower limit; this value is $8 \times 10^{-17} \mathrm{~s}^{-1}$. Taking this as the strain rate, Figure $21 d$ yields a minimum thermal gradient of $\sim 30 \mathrm{~K} \mathrm{~km}^{-1}$. This value is somewhat greater than previous estimates obtained by similar arguments [Zuber, 1987, Banerdt and Golombek, 1988]. The difference is attributable to the ability of Magellan to resolve buckling features with smaller wavelengths than were inferred from lowresolution data. Although Figure 21d suggests that the
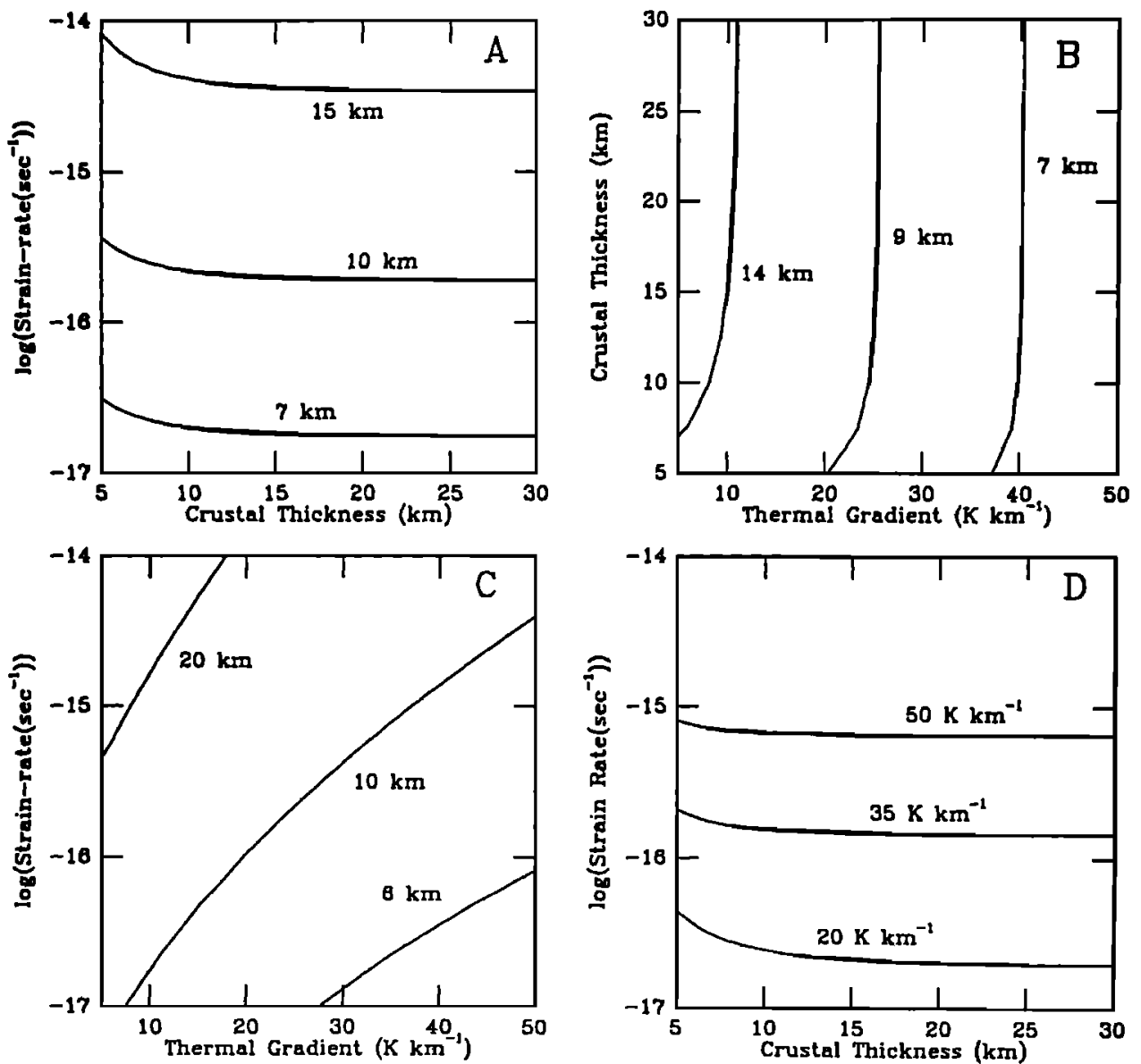

Fig. 21. Results of buckling calculations for the Venusian crust. (a) Dominant buckling wavelength as a function of strain rate and crustal thickness, assuming a thermal gradient of $25 \mathrm{~K} \mathrm{~km}^{-1}$. (b) Dominant buckling wavelength as a function of crustal thickness and thermal gradient, assuming a strain rate of $10^{-16} \mathrm{~s}^{-1}$. (c) Dominant buckling wavelength as a function of strain rate and thermal gradient, for a crustal thickness of $10 \mathrm{~km}$. (d) Thermal gradient as a function of strain rate and crustal thickness for a buckling wavelength ( $8 \mathrm{~km}$ ) typical of the values observed in the ridge belts of Lavinia Planitia. 
crustal thickness is not well constrained, the thickness of the elastic core is well constrained, with a value near about $200 \mathrm{~m}$ over the entire parameter space.

As noted above, these results assume complete decoupling between the crust and mantle. If some degree of coupling does exist, as we assumed in the convection model above, the buckling wavelengths presented here would increase [Banerdt and Golombek, 1988], leading to still higher inferred thermal gradients. Conversely, the buckling wavelengths would decrease if lithospheric strengths are reduced near the brittle-ductile transition by semibrittle deformation processes [Kirby, 1980]. Finally, we note that there is significant uncertainty in the choice of creep law parameters for the Venusian crust and that changes in a number of parameters chosen could have a significant effect on the results.

\section{Conclusions}

The Magellan spacecraft has provided the first detailed look at the deformation belts of the Venusian lowland plains. In some ways, these observations appear consistent with pre-Magellan expectations. The belts are elevated zones of intense tectonic deformation, and plausible arguments may be made that they are the consequence of crustal shortening and thickening. The observed scales and spacings of the belts may yield information about the strength properties of the lower crust and upper mantle, and the spacings of tectonic features within the belts may carry information about the strength properties of the upper crust [ $Z$ uber, 1987, 1990]. However, there are some surprises as well, the most notable one being the fact that there are two distinct types of belt morphology. We ultimately must understand the reasons for these differing morphologies, and how they may be related to the orthogonal pattern of smaller deformational features that transects the plains. Perhaps the most important part of this process will be the examination of future Magellan data. These data for Lavinia will include additional SAR images at incidence angles that will allow stereographic determination of topography, along with high-resolution mapping of the planet's gravity field. Moreover, images of other deformation belts, particularly those in Atalanta Planitia, have only recently become available for detailed study. A systematic comparison of the deformation belts throughout Venus will provide a foundation for further modeling of belt formation and evolution.

Acknowledgments. This work would not have been possible without the spectacular success of the Magellan Project, and we are indebted to the entire Magellan team for their efforts. We are also grateful to Daniel Janes and Peter Ford for helpful discussions, Aparna Venkatesan and Lesley Wright for image processing support, and Bruce Bills and Matt Golombek for constructive reviews. This work was supported by the Magellan Project.

\section{REFERENCES}

Anderson, E.M., The Dynamics of Faulting and Dyke Formation With Applications to Britain, 2nd ed., 206 pp., Oliver and Boyd, Edinburgh, 1951.
Banerdt, W. B., and M. P. Golombek, Deformational models of rifting and folding on Venus, J. Geophy. Res., 93, 4759-4772, 1988.

Barsukov, V. L. et al., The geology and geomorphology of the Venus surface as revealed by the radar images obtained by Veneras 15 and 16, Proc. Lunar Planet. Sci. 16th, Part 2, J. Geophys. Res., 91, Suppl., D378-D398, 1986.

Basilevsky, A.T., A.A. Pronin, L.B. Ronca, and V.P. Kryuchkov, Styles of tectonic deformation on Venus: Analysis of Venera 15 and 16 data, Proc. Lunar Planet. Sci. Conf., 16th, Pert 2, J. Geophys. Res.91, Suppl., D399-D411, 1986.

Bills, B.G., W.S. Kiefer, and R.L. Jones, Venus gravity: A harmonic analysis, J. Geophys. Res., 10,335-10,351, 1987.

Bindschadler, D. L., and E. M. Parmentier, Mantle flow tectonics: The influence of a ductile lower crust and implications for the formation of topographic uplands on Venus, J. Geophys. Res., $95,21,329-21,344,1990$.

Bindschadler, D.L., G. Schubert, and W.M. Kaula, Mantle flow tectonics and the origin of Ishtar Terra, Venus, Geophys. Res. Lett., 17, 1345-1348, 1990.

Biot, M. A., Theory of folding of stratified viscoelastic media, and its implications for tectonics and orogenesis, Bull. Geol. Soc. Am., 72, 1595-1620, 1961.

Brace, W. F., and D. L. Kohlstedt, Limits on lithospheric stress imposed by laboratory experiments, J. Geophy. Res., 85, 6248-6252, 1980.

Byerlee, J., Friction of rocks, Pure Appl. Geophys., 116, 615-626, 1978.

Campbell, D. B., J. W. Head, J. K. Harmon, and A. A. Hine, Venus: Identification of banded terrain in the mountains of Ishtar Terra, Science, 221, 644, 1983.

Caristan, $Y$., The transition from high temperature creep to fracture in Maryland diabase, J. Geophys. Res., 87, 6781-6790, 1982.

Crumpler, L.S., J. W. Head, and D. B. Campbell, Orogenic belts on Venus, Geology, 14, 1031-1034, 1986.

Golombek, M.P., Fault type predictions from stress distributions on planetary surfaces: Importance of fault initiation depth, $J$. Geophys. Res., 90, 3065-3074, 1985.

Kiefer, W. S., M.A. Richards, B.H. Hager, and B.G. Bills, A dynamic model of Venus's gravity field, Geophys. Res. Lett., 19, 14-17, 1986.

King, S. D., A. Raefsky, and B. H. Hager, ConMan: Vectorizing a finite element code for incompressible two-dimensional convection in the Earth's mantle, Phys. Earth Planet. Inter., 59, 195-207, 1990.

Kirby, S. H., Tectonic stresses in the lithosphere: Constraints provided by the experimental deformation of rocks, J. Geophys. Res., 85, 6353-6363, 1980.

McAdoo, D. C., and D. T. Sandwell, Folding of oceanic lithosphere, J. Geophys. Res., 90, 8563-8569, 1985.

Pettengill, G. H., P. G. Ford, W.T.K. Johnson, R. K. Raney, and L. A. Soderblorn, Magellan: Radar performance and data products, Science, 252, 260-265, 1991.

Phillips, R.J., A mechanism for tectonic deformation on Venus, Geophys. Res. Lett., 13, 1141-1144, 1986.

Phillips, R. J., Convection-driven tectonics on Venus, J. Geophys. Res., 95, 1301-1316, 1990.

Phillips, R. J., R. E. Grimm, and M. C. Malin, Hot-spot evolution and the global tectonics of Venus, Science, 252, 651-658, 1991.

Plescia, J.B., and M.P. Golombek, Origin of planetary wrinkle ridges based on study of terrestrial analogs, Geol. Soc. Am. Bull, 97, 1289-1299, 1986.

Schmeling, H., and G. Marquart, A mechanism for crustal thinning without lateral extension, Geophys. Res. Lett., 17, 2417 $2420,1990$.

Schultz, R.A., and M.T. Zuber, The paradox between predicted and observed occurrences of faults surrounding planetry surface loads (abstract), Eos Trans. AGU, 72, 285, 1991.

Simons, M., S.C. Solomon, and B.H. Hager, Dynamic models for ridge belt formation on Venus (abstract), Lunar Planet. Sci., 21, 1263-1264, 1991.

Smrekar, S.E., and R.J. Phillips, Venusian highlands: Geoid to topography ratios and their implications, Earth Planet. Sci. Lett., 107, 582-597, 1991.

Solomon, S.C., J.W. Head, W.M. Kaula, D. McKenzie, B. Parsons, R.J. Phillips, B. Parsons, G. Schubert, and M. Talwani, 
Venus tectonics: Initial analysis from Magellan, Science, 252, 297-312, 1991.

Solomon, S.C., et al., Venus tectonics: An overview of Magellan observations, J. Geophys. Res., this issue.

Stofan, E.R., V.L. Sharpton, G. Schubert, G. Baer, D.L. Bindschadler, D.M. Janes, and S.W. Squyres, Global distribution and characteristics of coronae and related features on Venus: Implications for origin and relation to mantle processes, $J$. Geophys. Res., this issue.

Sukhanov, A.L., and A.A. Pronin, Ridged belts on Venus as extensional features, Proc. Lunar Planet. Sci., 19th, 335-348, 1989.

Turcotte, D. L., and G. Schubert, Geodynamics, Applications of Continuum Physics to Geologic Problems, 450 pp., John Wiley, New York, 1982.

Watters, T.R., Wrinkle ridge assemblages on the terrestrial planets, J. Geophys. Res., 99, 10,236-10,254, 1988.

Zuber, M. T., Constraints on the lithospheric structure of Venus from mechanical models and tectonic surface features, Proc. Lunar Planet. Sci. Conf. 17th, Part 2, J. Geophys. Res., 92, Suppl., E541-E551, 1987.
Zuber, M. T., Ridge belts: Evidence for regional- and large-scale deformation on the surface of Venus, Geophys. Res. Lett., 17, 1369-1372, 1990.

B.H. Hager, M. Simons, and S. C. Solomon, Department of Earth, Atmospheric, and Planetary Sciences, Massachusetts Institute of Technology, Cambridge, MA 02139.

D. G. Jankowski and S. W. Squyres, Center for Radiophysics and Space Research, Cornell University, Ithaca, NY 14853.

George E. McGill, Department of Geology and Geography, University of Massachusetts, Amherst, MA 01003.

(Received October 11, 1991; revised May 11, 1992 ; accepted May 11, 1992.) 